\title{
Towards a developmental model of musical empathy using insights from children who are on the autism spectrum or who have learning difficulties
}

Introduction

This chapter interrogates the notion of 'musical empathy' (Livingstone and Thompson, 2009), and considers whether it is distinct from the widely acknowledged 'emotional' and 'cognitive' forms of empathy that function for most people in everyday life (Davis, 1996): that is, whether it is possible for one person to discern and appreciate others' musical perspectives, without necessarily being able to identify more generally with their thoughts or feelings. It is suggested that musical empathy may itself be of two types, 'affective' and 'cognitive', and that these pertain to the 'content' and 'structure' of music that, according to zygonic theory (Ockelford, 2005, 2012), make up the warp and the weft of the musical fabric. A challenge of this line of thinking is being able to identify contexts in which musical empathy may potentially be isolable from 'everyday' empathetic thoughts and feelings, and a novel approach is adopted here, which considers case studies of children who are on the autism spectrum or who have learning difficulties (or both). This is because while research shows that children with autism generally find it difficult to grasp how others think and feel, typically lacking 'theory of mind' (BaronCohen, 1995), there is evidence to suggest that, in some cases, music may have the capacity to act as a vehicle through which they can relate empathetically to other people (Ockelford, 2013; Greenberg, Rentfrow and Baron-Cohen, 2015).

Previous research with children with intellectual disabilities, as part of the Sounds of Intent project (Welch et al., 2009; Cheng, Ockelford and Welch, 2010; Vogiatzoglou et al., 2011), suggests that, while these young people tread essentially the same music-developmental path as their 'neurotypical' peers, the stages of musical understanding that they attain take longer to evolve and so are easier to capture, facilitating their identification. The research has had to address certain difficulties, however, including the fact that such children may be non-verbal, or at least have little or no capacity for metacognition. As a consequence, data tend to be in the form of musical rather than verbal products, requiring the specialised music-analytical tools offered by zygonic theory to track musical intentionality and influence (Ockelford, 2012).

The results of such analysis undertaken in this study provide evidence that musical empathy may indeed exist as a discrete phenomenon, with distinct stages of development that run in parallel to the six music-developmental levels identified in Sounds of Intent. These entail 
traversing an ontogenetic path that potentially ranges from a state in which one has no sense of self or of other people (Level 1) to the position of having the (intuitive) notion of a protomusical self and other (Level 2); thence having the recognition that there are others who are musically 'like me', in the moment, (Level 3) to those who are 'like me, yet different', to whom one can relate beyond the perceived present (Level 4); and so to an awareness that it is possible to share a musical journey with another or others through taking a common structural path (Level 5) and finally to a realisation that two musicians or more can work together to create a blended cognitive-emotional narrative in sound (Level 6). Here musical empathy can extend beyond an understanding of the thinking and feelings of the individuals concerned to having a sense of the musical psyche of a wider cultural community.

\section{What is empathy?}

Through introspection and observation, philosophers and psychologists have identified two types of empathy: the kind through which we directly come to share the emotions of others, through an extension of 'emotional contagion' ('catching' the emotional states of others through being in their presence when they are showing how they feel), and the sort that enables us figuratively to put ourselves in others' shoes, and appreciate their situation on an intellectual level (mental activity that may well also have an affective component) - the capacity for socalled 'theory of mind' (see, for example, Håkansson, 2003; de Waal, 2008; Coplan, 2011). In recent years, this dual classification has received some neuroscientific support (for example Shamay-Tsoory, Aharon-Peretz and Perry, 2009; Goldman, 2011).

A good deal of theoretical and empirical attention has also been devoted to the related issue of how empathy arises in human development (McDonald and Messsinger, 2011), in particular exploring Andrew Meltzoff's contention that infant imitation (which starts in neonates) leads to the perception of other people as being 'like me', and that others who act in the way that I do are likely to have internal states that are 'like mine' (Meltzoff and Moore, 1983, 1989; Meltzoff, $1990,1995,2002,2005)$. Some believe that a system of mirror neurons, which are activated not only when a person undertakes a particular action, but also when the same action is merely observed in another (Di Pellegrino et al., 1992; Gallese et al., 1996; Rizzolatti et al., 1996; Cattaneo and Rizzolatti, 2009) may lie at the heart of empathetic responses (for example, Preston and de Waal, 2002; Carr et al., 2003; Gallese, 2003; Miall, 2003; Decety, 2004; Iacoboni, 2009; Keysers, 2011). Of particular interest in the current context is the finding that mirror neurons may be triggered by sounds as well as visual images (Kohler, 2002), and that, through 
this process, auditory input is capable of stimulating empathetic reactions too (Gazzola, AzizZadeh and Keysers, 2006).

It is possible to model a mature empathetic response as shown in Figure 1, which sets out the potential routes through which one person's feelings or thoughts (or both) may be transferred to another. For example, Person A could convey what she or he thinks or feels (often, though not necessarily, elicited by a given set of external circumstances) through language, observable behaviours or actions. These may be detected by Person B, and the mental imagery so generated evoke similar thoughts and feelings to those of Person A. It is also possible for Person B to observe Person A experiencing a given set of circumstances and for these to elicit thoughts or feelings directly.

This model makes certain assumptions. For the successful transmission of thoughts or feelings to occur and for empathy to be engendered requires that Person B has had a previous experience that has enough in common with that encountered by Person A to allow this to be appreciated; that Person B and Person A share the connotations of the language, behaviour or action that are present; that Person B reacts cognitively or affectively in the same way as Person A to a given set of circumstances; and that Person B is aware that his or her thoughts or feelings are elicited by the situation or disposition of Person A.

There are potential complications too. For example, Person B can experience empathy for someone who does not exist (who is purely imagined, or whose persona is conjured up in a novel, play, film or cartoon, for example); Person A may consciously seek to elicit empathetic thoughts (where none is actually merited) in Person B through pretence; and Person B may experience empathy for Person A who has no related thoughts or feelings - for example, Person B may be aware that a tragedy is about to befall Person A, who is, however, ignorant of what is shortly going to occur. 


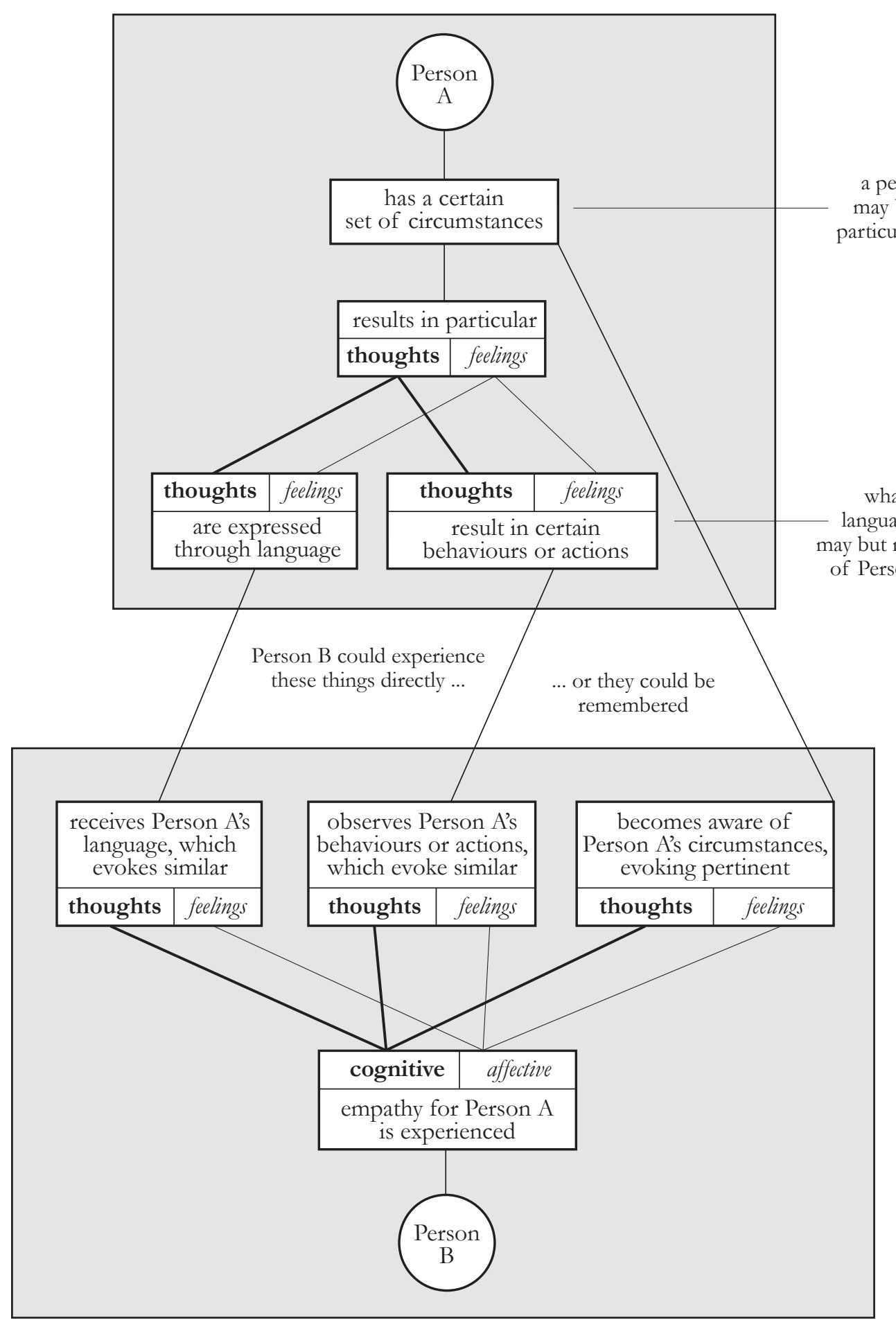

a person's circumstances

may but need not result in

particular thoughts or feelings

what is expressed through

hence empathy could be elicited in Person B without comparable thoughts or feelings being experienced by Person A

empathy demands that

Person B has had experiences that are sufficiently similar to Person A's

(for example, feeling pain or sorrow)

to allow these to be imagined and appreciated Person B and Person A share the connotations of the language, behaviour or action that is present

Person B reacts cognitively or affectively in the same way as Person A to a given set of circumstances

Figure $1 \mathrm{~A}$ model of how empathy may be engendered in everyday contexts.

\section{Musical empathy: initial questions}

Unsurprisingly, perhaps, given music's potential for conveying emotion and creating a sense of interpersonal connection, the notion of empathy has come to the notice of some researchers in the fields of music psychology and education, including, for example, Patrik Juslin (Juslin, 2001, 2008; Juslin and Västfjäll, 2008), who contends that listeners perceive the emotional expression 
conveyed by musicians in performance then 'mimic' this expression internally, and Seddon (1999) and Cross, Laurence and Rabinowitch (2012), who advance the idea of 'empathic creativity', through which interpersonal attunement may occur in group musical interaction.

But what is 'musical empathy'? Is it ultimately the same as 'everyday' empathy, but elicited via a different route (through abstract patterns of sound rather than words or actions, for example)? Or is it a way of sharing thoughts and feelings that is fundamentally different? Or can it be either according to context? (See Figure 2.)

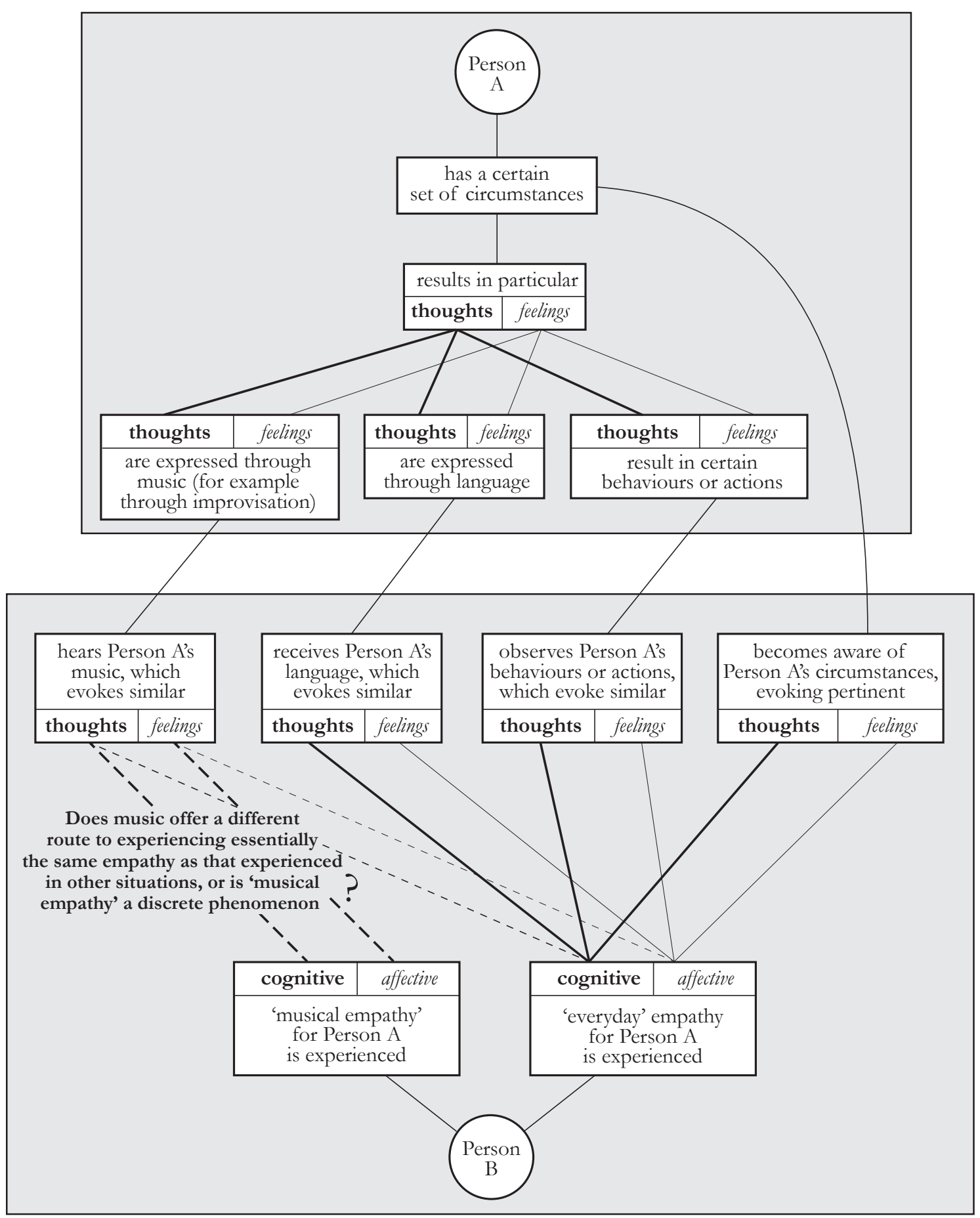


Figure 2 What is 'musical empathy'?

To facilitate analysis of this issue, we will consider a group in whom musical empathy and 'everyday' empathy appear to be uncoupled - those on the autism spectrum.

\section{Autism and empathy}

Empathy has become a focus of research in the area of autism, since emotional contagion and theory of mind are generally held by psychologists to be two of the principal deficits of those on the spectrum (for example, Happé, 1998; Frith, 2003; Baron-Cohen, 2005; Boucher, 2008). The conjecture that a defective mirror neuron system may be a contributory - even primary factor in this developmental lacuna has found widespread (though not universal) support: see, for instance, Oberman et al. (2005), Williams et al. 2006); Ramachandran and Oberman (2006), Hadjikhani (2005), Fan et al. (2010) and Rizzolatti and Fabbri-Destro (2010). At the same time, while there are some accounts of young people on the autism spectrum playing music inexpressively or with scant regard to the aesthetic intent of fellow performers (Winner, 1996, p. 136), other studies have suggested that autistic children can detect the intended emotional import of music just as well as their neurotypical peers (Heaton, Hermelin and Pring, 1999), and can perform with great sensitivity, with an awareness of the impact of their playing and singing on others and sensible to the expressive aspirations of other performers in ensembles (Ockelford, 2008, 2013). Indeed, it has been suggested that music-making with others may provide a vehicle for engaging the mirror neuron system in children on the autism spectrum (Wan et al., 2010).

Hence there may be a mismatch between the degree of empathy exhibited by people with autism in day-to-day life and that which they display (and so presumably experience) during musical engagement with others. Take, for example, Romy (of whom we will hear more later), who, at the time of writing, is 14 years old, severely developmentally delayed, with no formal expressive language, and with many of the characteristics of autism: she appears to be oblivious to the emotional states of those around her (the obverse of her infectious, effervescent egocentricity), and would be wholly unable to appreciate another's point of view on an intellectual level through theory of mind. However, she is a young musician of extraordinary sensitivity, and enjoys playing familiar melodies on the piano with her right hand alone to the author's improvised accompaniments, not only following the tempo, dynamics, and articulation that are offered (in accordance with the expressive conventions of Western classical 
performance), but also predicting what her co-performer is likely to do next: delaying the placement of notes at the climaxes of phrases, for example, and even pushing the temporal envelope through rubato further than in the model that is provided. Observers comment on how Romy not only appears to have an intuitive understanding of the emotional narrative of the music that is projected from the accompaniment, but that they find her playing musically persuasive and genuinely moving - a feeling that she seems to share, as she will often vocalise excitedly at the melodic climaxes that she articulates so compelling and vigorously flap her left hand (both indicators of a positive affective response), as though intoxicated by the products of a shared musical discourse.

So what is happening here? To reiterate our central question: is the empathy that Romy is able to experience in a musical context different from 'everyday' empathy? Or does music offer a route to empathetic engagement with another that she cannot otherwise access? In either case, is this something that is unique to Romy, or to people with autism and learning difficulties more generally, or could it be that many (or all) of us have the potential to experience a distinct, musical form of empathy? And if musical empathy does exist as a mental entity in its own right, does it evolve in line with a child's musical development?

We will address these issues through a series of case studies of children at different stages in the development of their musical abilities. We will structure our discussion in terms of the Sounds of Intent framework, which, created through over a decade of research in the field, seeks to map musical development in children and young people with learning difficulties, including those with autism (see, for example, Ockelford et al., 2005; Welch et al., 2009; Cheng, Ockelford and Welch, 2010; Ockelford and Matawa, 2010; Ockelford et al., 2011; Vogiatzoglou et al., 2011). Underpinning Sounds of Intent is 'zygonic' theory, which sets out to explain how music works as a communicative medium: how it is that abstract patterns of sound are able to convey meaning, and what the nature of that meaning is. And it is to this theory that we now turn our attention.

\section{The zygonic conjecture}

In seeking to describe zygonic theory, we will consider first the issue of meaning in languagebased art forms, which, as a reflection of an external 'reality' or potential, have a more evident source of meaning construction. According to T.S. Eliot (1933; 1960), literature has three principal sources of meaning (couched in terms of aesthetic response):

- an objective correlative - a set of objects, a situation, a chain of events, which shall be the 
'formula of a particular emotion';

- the manner of representation (including, for example, the use of metaphor);

- the sound qualities and structure of the language itself.

This thinking may be represented as shown in Figure 3. In semiotic terms, the model captures the stages corresponding to the transition from:

- semantics (the relationships between signs and the things to which they refer); through

- syntactics (the relationships between signs); to

- pragmatics (the relationships between the signs and the effects they have on readers or listeners).

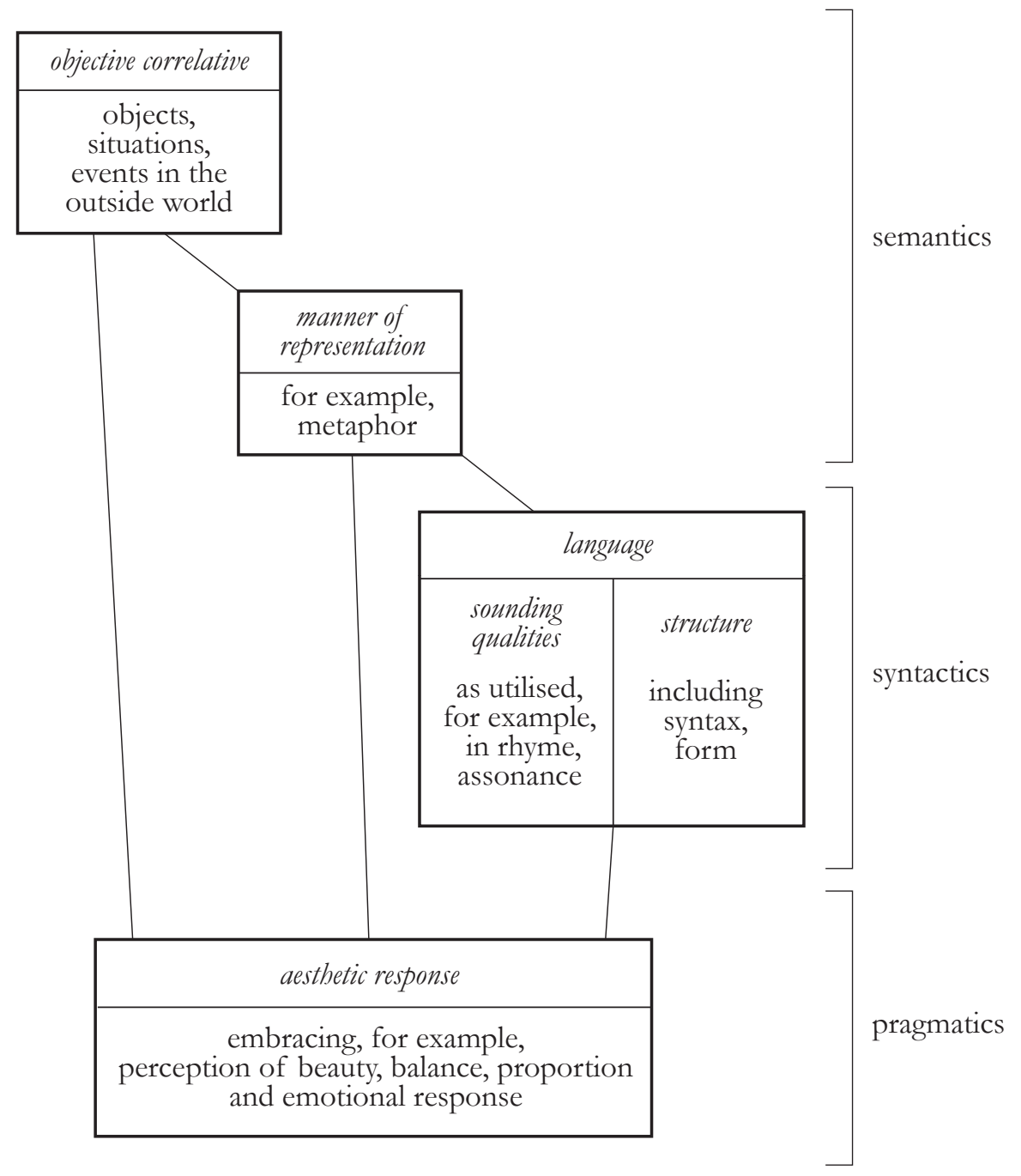

Figure 3 Representation of T.S. Eliot's model of aesthetic response to literary works, and its correspondence to semiotic thinking. 
However, absolute music (and the abstract component of music with referential meaning) has no objective correlative - no semantic component (see Figure 4). In these circumstances, how is meaning constructed and conveyed?

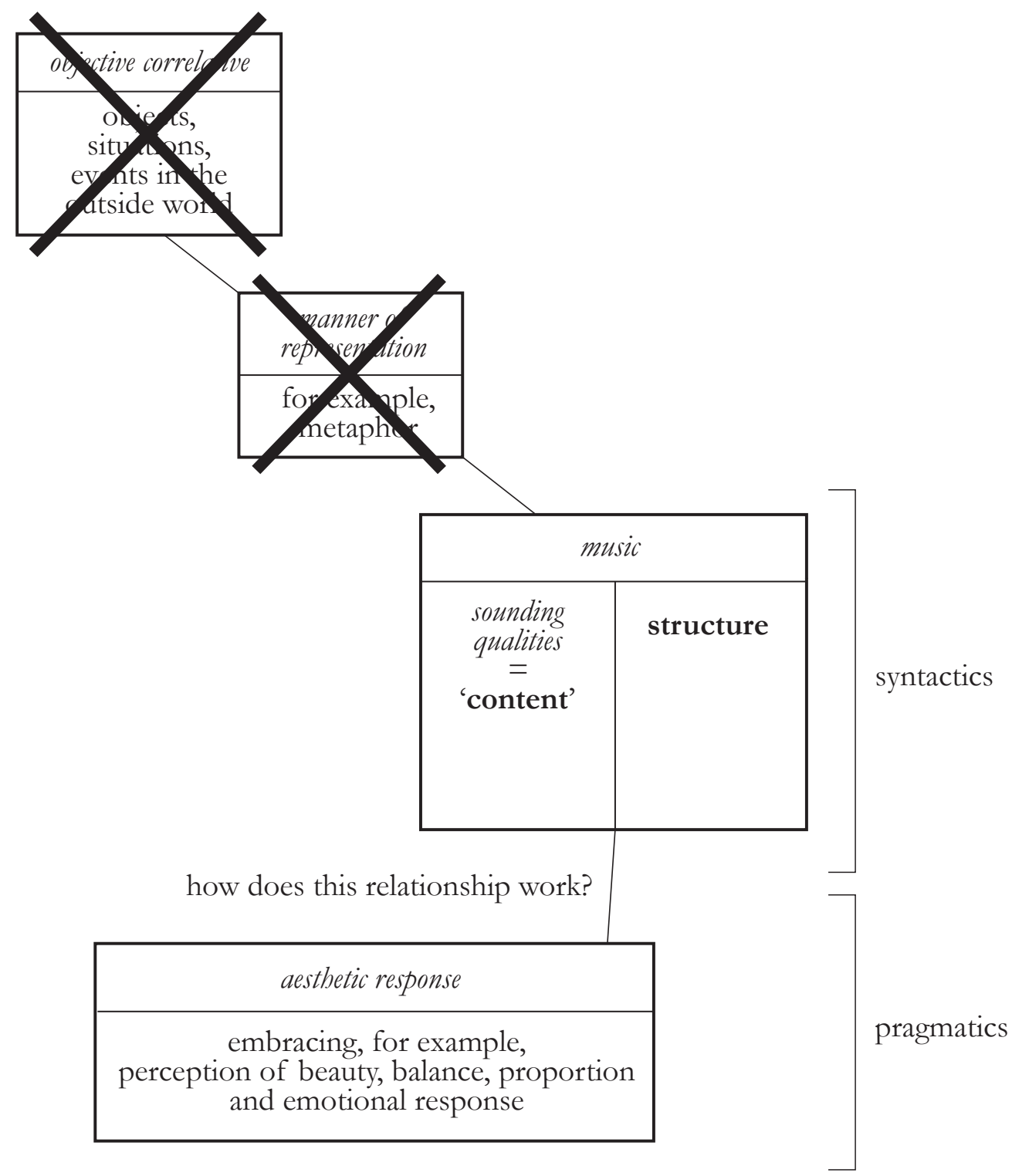

Figure 4 Absolute music has no objective correlative - so how is meaning conveyed?

In the absence of semantics, it follows that the meaning of music must derive solely from its syntax - the logical arrangement of its constituent sounds - which has two elements: the qualities of the sounds themselves (in zygonic theory referred to as 'content') and their organisation (termed 'structure').

First, we consider 'content'. Zygonic theory asserts that all sounds and the relationships we perceive between them can potentially cause or enable an emotional response ( $c f$. Johnson- 
Laird and Oatley, 1992; Sparshott, 1994, p. 28). There appear to be two main sources of such responses (a) 'expressive non-verbal vocalisations' and (b) 'music-specific' qualities of sound.

'Expressive non-verbal vocalisations' comprise the cues used to express emotions vocally in non-verbal communication and speech (Juslin, Friberg and Bresin, 2001). They are present cross-culturally (Scherer, Banse and Wallbott, 2001), suggesting a common phylogenetic derivation from 'non-verbal affect vocalisations' (Scherer, 1991) and apparently embedded ontogenetically in early maternal/infant interaction (Malloch, 1999; Trehub and Nakata, $2001 / 2002)$. It seems that these cues can be transferred in a general way to music, and musicpsychological work from the last 70 years or so has shown that features such as register, tempo and dynamic level do relate with some consistency to particular emotional states (Gabrielsson and Lindström, 2001). For example, passages in a high register can feel exciting (Watson, 1942) or exhibit potency (Scherer and Oshinsky, 1977), whereas series of low notes are more likely to promote solemnity or to be perceived as serious (Watson, op. cit.). A fast tempo will tend to induce feelings of excitement (Thompson and Robitaille, 1992), in contrast to slow tempi that may connote tranquility (Gundlach, 1935) or even peace (Balkwill and Thompson, 1999). Loud dynamic levels are held to be exciting (Watson, op. cit.), triumphant (Gundlach, op. cit.) or to represent gaiety (Nielzén and Cesarec, 1982), while quiet sounds have been found to express fear, tenderness or grief (Juslin, 1997). Conversely, as Leonard Meyer observes (2001, p. 342), 'one cannot imagine sadness being portrayed by a fast forte tune played in a high register, or a playful child being depicted by a solemnity of trombones'.

'Music-specific' qualities of sound, like those identified above in relation to early vocalisation, have the capacity to induce consistent emotional responses, within and sometimes between cultures. For example, in the West and elsewhere, music typically utilises a framework of relative pitches with close connections to the harmonic series. These are used idiosyncratically, with context-dependent frequency of occurrence and transition patterns, together yielding the sensation of 'tonality' (Krumhansl, 1997; Peretz, Gagnon and Bouchard, 1998). These frameworks of relative pitch can accommodate different 'modalities', each potentially bearing distinct emotional connotations. In Indian music, for example, the concept of the 'raga' is based on the idea that particular patterns of notes are able to evoke heightened states of emotion (Jairazbhoy, 1971/1995), while in the Western tradition of the last four centuries or so, the 'major mode' is typically associated with happiness and the 'minor mode' with sadness (Hevner, 1936; Crowder, 1985), differences which have been shown to have neurological correlates (Suzuki, et al., 2008; Nemoto, Fujimaki and Wang, 2010). 
On their own, however, separate emotional responses to a series of individual sounds or clusters would not add up to a coherent musical message - a unified aesthetic response that evolves over time. So what is it that binds these discrete, abstract experiences together to form a cogent musical narrative? It is my contention that organising force is 'structure', as defined in zygonic theory.

To understand how this works, consider verbal language once more. Eliot's 'objective correlative' is likely to be a series of events, actions, feelings or thoughts that are in some way logically related, each contingent on another or others through concepts such as causation.

Relationships like these will be conveyed and given additional layers of meaning through language-specific relationships such as metaphor (in the domain of 'manner of representation'), rhyme and meter (in the domain of 'sounding qualities') and syntax (in the domain of 'structure') - see Figure 5.

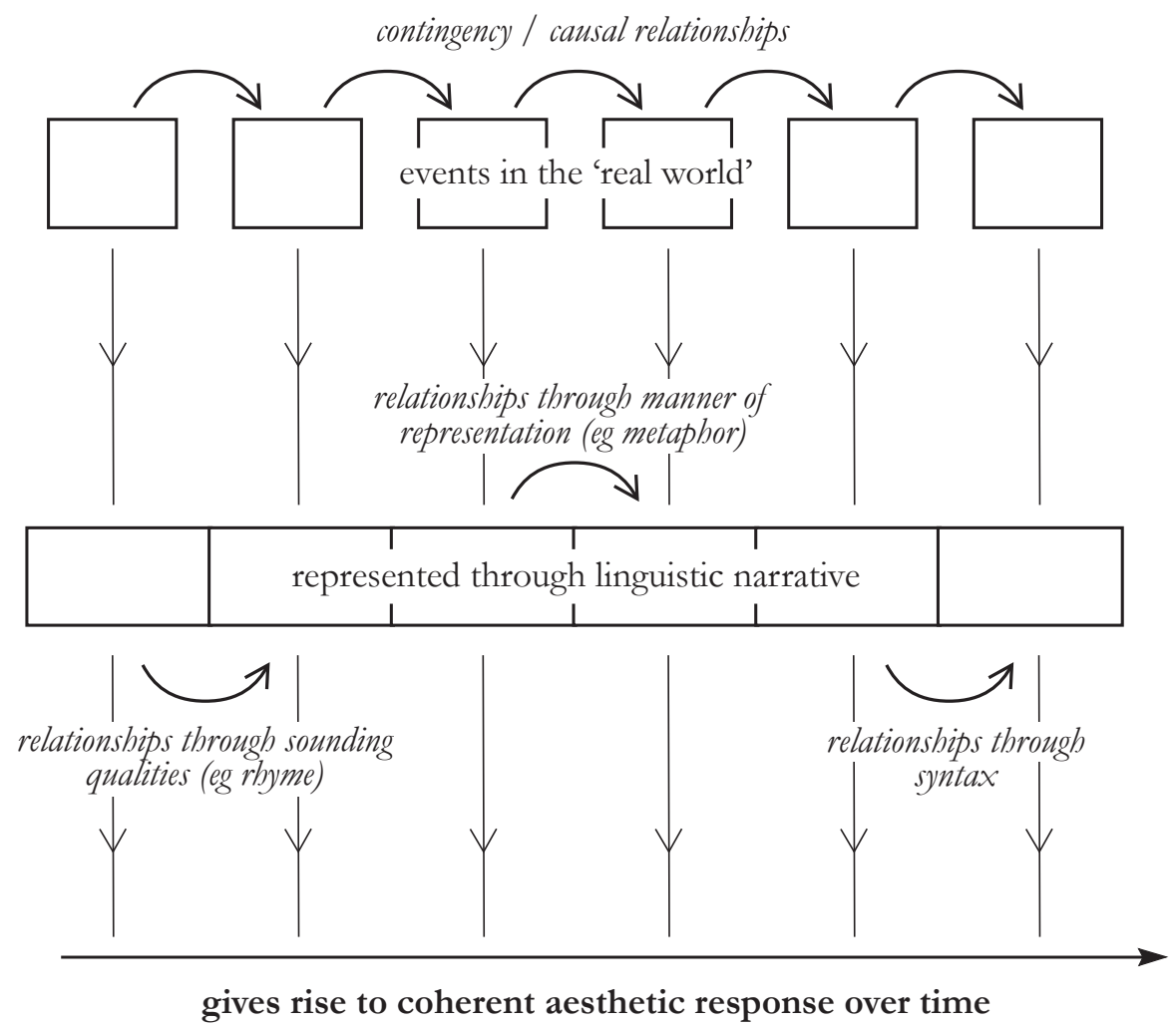

Figure 5 The forms of logical relationship underpinning meaning in language.

But how does a comparable sense of coherence and unity - a sense of structure - come about in music, when it cannot borrow a sense of contingency from the external world? In the absence of an objective correlative, musical events can refer only to themselves (Selincourt, 1920). Self-evidently, one sound does not cause another one to happen (it is performers who do that), but one can imply another (Meyer, 1989, pp. 84ff) through a sense of derivation. That is, one 
musical event can be felt to stem from another, and it is my contention that this occurs through imitation: if one fragment or feature of music echoes another, then it owes the nature of its existence to its model. And just as certain perceptual qualities of sound are felt to derive from one another, so too, it is hypothesised, are the emotional responses to each. Hence over time a metaphorical (musical) narrative can be built up through abstract patterns of sound.
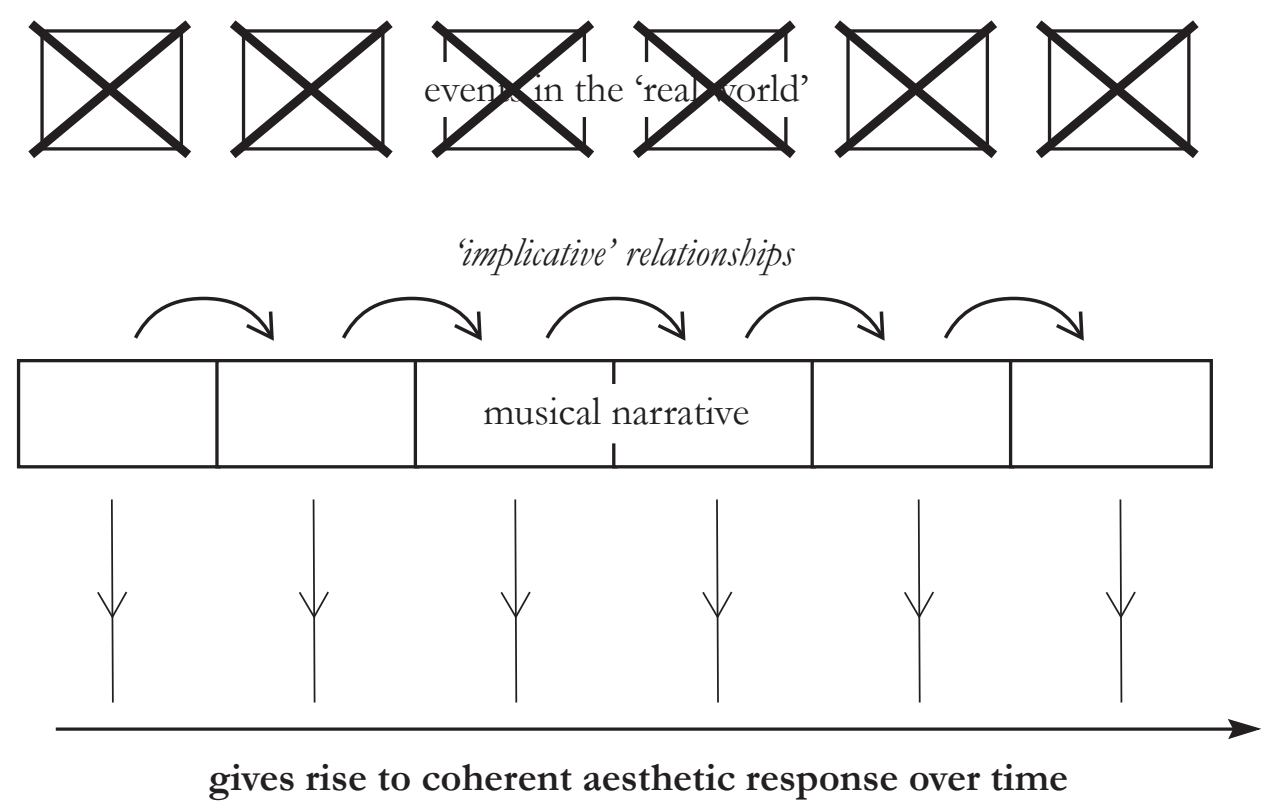

Figure 6 Relationships underpinning logic in music.

The agency through which musical implication occurs is held to be a particular kind of perceived relationship that acknowledges the qualities of separate sounds that are the same or similar. Such relationships - purely mental constructs - are termed 'zygonic', after the Greek 'zygon', meaning a 'yoke' or connection between similar things (Ockelford, 1991). The musical effect of a zygonic relationship is that a second event seems to derive from one that precedes, or, conversely, that a given event appears to generate one that follows. The underlying imitation can be exact or approximate, and refer to part or the whole of a musical event. Relationships can be of different levels: 'primary', between percepts themselves; 'secondary', between perceptual differences; and 'tertiary', between the relationships between differences. 

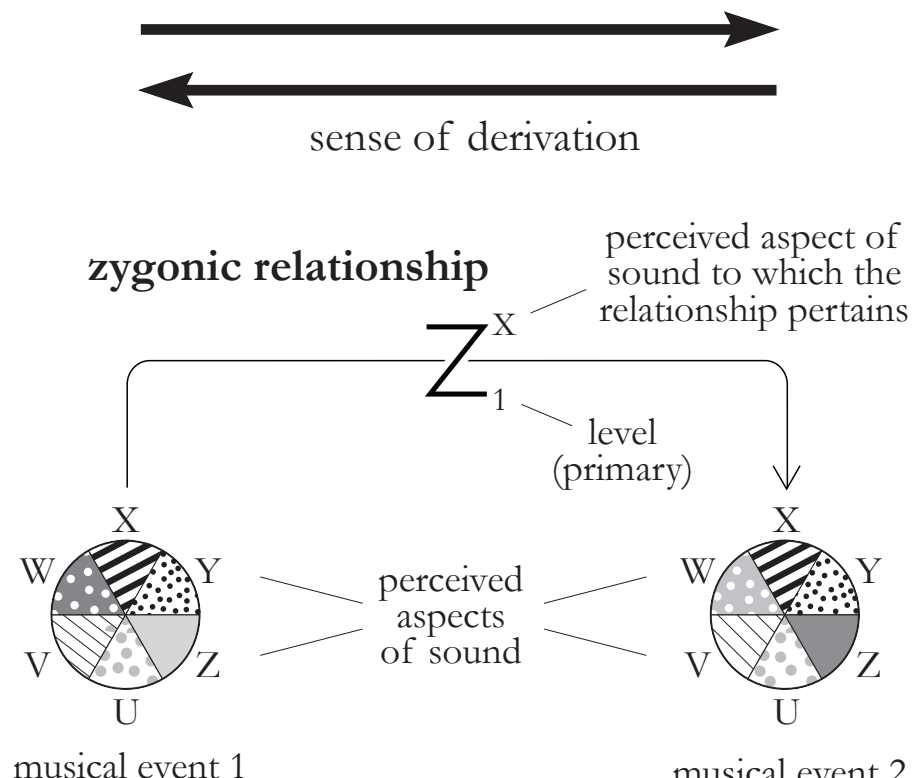

Figure 7 Representation of primary zygonic relationship.

Zygonic theory holds that the cognition of musical structure occurs at three levels in the domains of pitch and perceived time, and that these pertain to 'events', 'groups' and 'frameworks' (Ockelford, 2006, 2011). Essentially the same conjecture pertains to groups and frameworks as to events: that musical structure will be cognised when one musical element or feature is heard as imitating another. Given young children's propensity to copy sounds and to relish being copied, it seems that the neural correlates of zygonic relationships must emerge early in the development of cognition, with the capacity to function both reactively (that is, recognising the imitation of one musical event by another) and proactively (creating one musical event by copying another). How this ability subsequently evolves to enable young listeners to gauge the similarities between groups of sounds and between the imaginary, probabilistic frameworks of pitch and perceived time within which pieces of music are typically cast, is the subject of other research (Ockelford and Voyajolu, n.d.). For example, the way in which zygonic relationships of pitch can function reactively between events, groups and frameworks to create perceived coherence at different structural levels, and the cognitive demands that each is hypothesised to pose on listeners (see Figure 8) will be illustrated in relation to the opening bars of Beethoven's $5^{\text {th }}$ Symphony.

Recognising imitation between events is postulated to take the least mental processing power, requiring (at least) two items of musical information (which comprise notes in the current example) to be held in working memory and compared. The temporal envelope within which such structures occur and are perceived is generally constrained, sometimes extending to little 
more than the perceived present. Zygonic connections between groups necessarily involve four events or more (Ockelford, 2006, p. 109), whose temporal disposition is potentially far more variable, possibly implicating long-term memory. Here there may also be a greater degree of abstraction from the perceptual 'surface', when it is relationships between the events within each group that are being compared (as in the example shown - see Figure 9). Imitative links between frameworks appear to be the most cognitively demanding of all. They depend on the existence of long-term 'schematic' memories (Bharucha, 1987) - in the case of a listener stylistically attuned to the Beethoven symphony, for example, built up from substantial exposure to other pieces in the minor mode. Here, it is assumed that the details of the perceptual surface and individual connections perceived between musical events are not encoded in long-term memory discretely or independently, but are combined with many thousands of other similar data to create probabilistic networks of relationships between notional representations of pitch and perceived time. That is, large amounts of perceptual information are merged to enable the requisitely parsimonious deep level of cognitive abstraction to occur. 


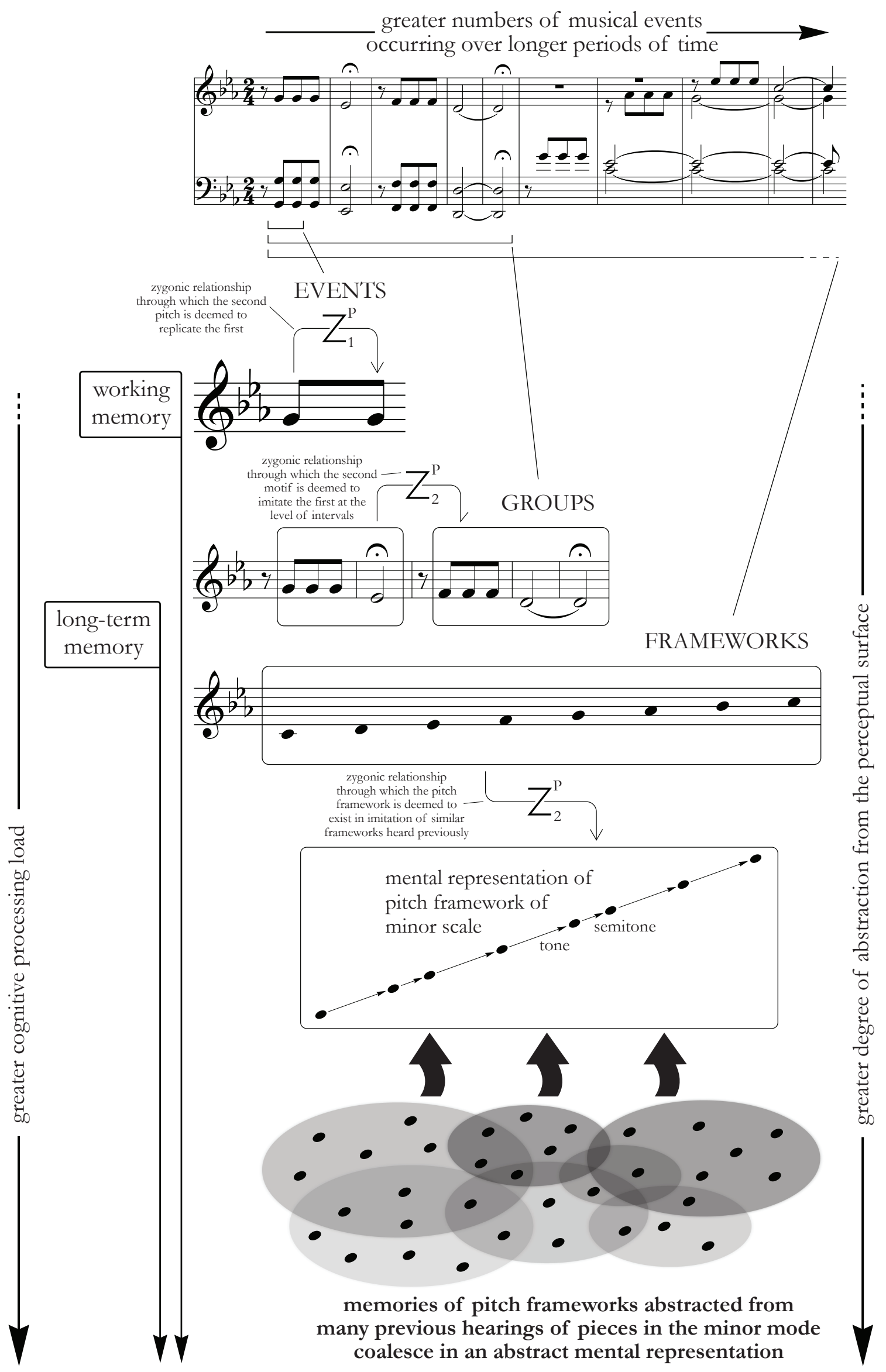

Figure 8 The differing cognitive demands of processing musical structure at the level of events, groups and frameworks. 


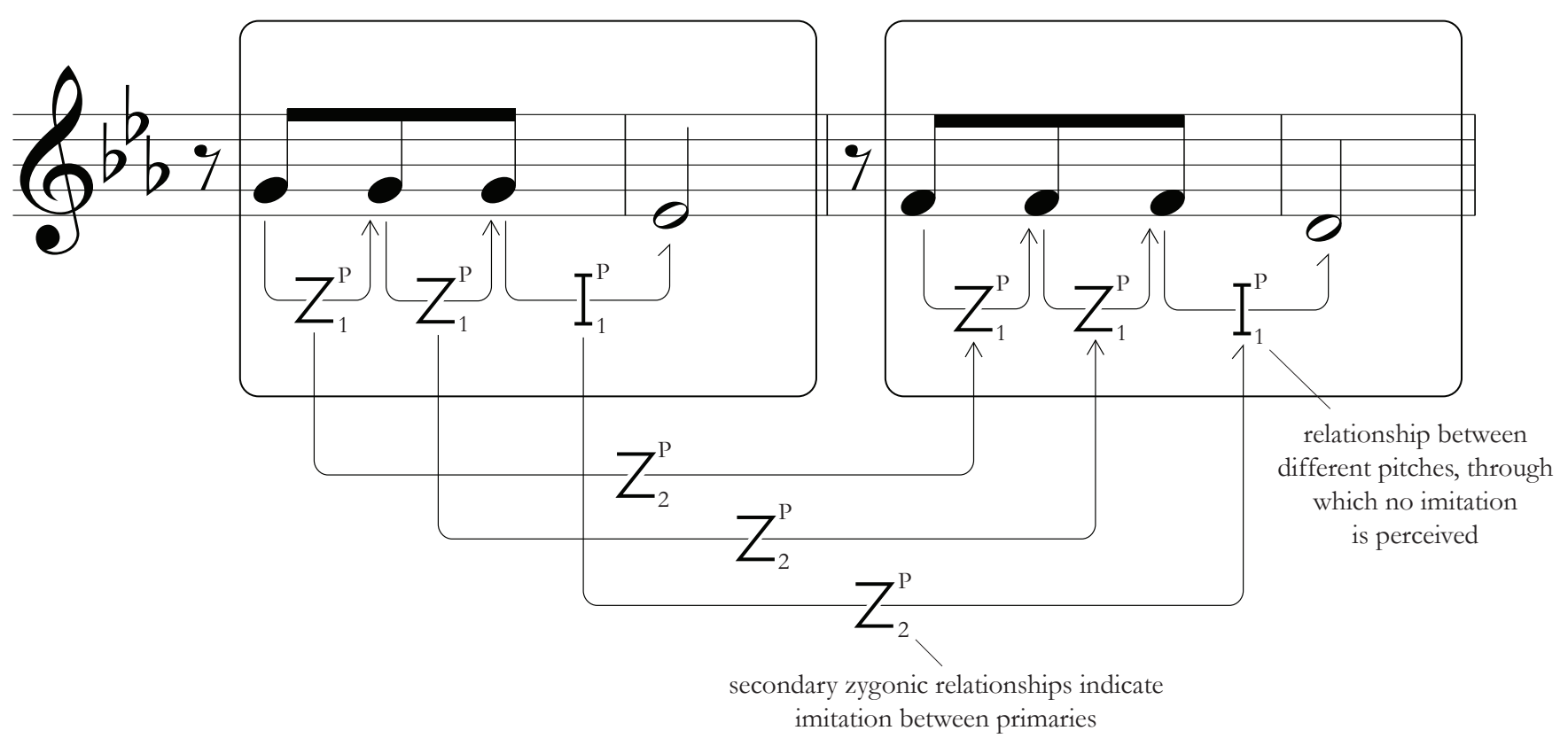

Figure 9 Zygonic connections between groups of notes frequently involve the cognition of relationships between relationships.

In summary, then, it is hypothesised that the cognitive correlates of musical structure grow in complexity as one moves from events to groups and frameworks, reflecting an increasing amount of perceptual input, experienced over longer periods of time, and processed and stored using progressively more abstract forms of mental representation. Moreover, the logic of the music-theoretical model suggests that the cognitive operations pertaining to higher levels of structure must build on and incorporate those required to process lower levels, since connections between groups comprise series of relationships between events (see Figure 9), and links between frameworks are established by acknowledging the correspondences that exist between groups.

\section{The Sounds of Intent project}

The existence of the cognitive correlates of musical structure (postulated above from the point of view of an enculturated listener of Western classical music) was first corroborated empirically in the Sounds of Intent studies, which were designed to explore the musical development of children with learning difficulties (for example, Ockelford et al., 2005; Cheng, Ockelford and Welch, 2009; Welch et al., 2009; Ockelford et al., 2011; Vogiatzoglou et al., 2011). Here, the evidence of music-structural processing pertaining to events, groups and frameworks comes 
from hundreds of observations of young people engaging with music in a range of everyday contexts.

For example, an appreciation of imitation at the level of events is implied by Zeeshan's laughing and rocking 'when he hears his teacher imitating Tom's vocal sounds', an understanding that is translated into action by Xavier, who 'distinctly tries to copy high notes and low notes in vocal interaction sessions' (Ockelford, 2012, pp. 130 and 133). Lottie seems to be able to recognise group structures, since she "cries whenever she hears the "goodbye" song. It only takes the first two or three notes to be played on the keyboard, and she experiences a strong emotional reaction.' This capacity is realised in sound by Lottie, who 'hums distinct patterns of notes and repeats them. Her favourite sounds rather like a playground chant, and she repeats it from one day to the next' (Ockelford, op. cit., pp. 129 and 130). Quincy, who 'knows that when his music teacher plays the last verse of Molly Malone in the minor key it signifies sadness' shows some non-conceptual understanding of how pitch frameworks work in the Western musical vernacular, while Janet, with severe learning difficulties, has taken Quincy's intuitive grasp of mode a stage further, having 'developed the confidence to introduce new material on her saxophone in the school's jazz quartet', Ockelford (ibid.).

Although much of the data gathered in the course of the Sounds of Intent project comprised 'snapshots' of children's musical engagement at a single point in time, rather than offering longitudinal accounts, two developmental features of music-structural cognition did become apparent. First, as one would expect, it appeared that the successively more extensive cognitive abilities required to process musical structure at the level of events, groups and frameworks arise sequentially in development. The evidence for this stemmed from the observation that there were no instances of children showing music-structural engagement at the level of frameworks who were not also able to recognise or create imitative patterns involving groups, nor of children who could process or produce group structures who could not also operate cognitively at the level of events. Second, it became evident that the cognitive capacities pertaining to each structural level do not emerge fully functioning, but themselves evolve incrementally: that is to say, as well as music-structural processing developing between levels, there also appeared to be development within each of them.

In addition, the Sounds of Intent data suggested precursors to the three stages of music-structural cognition whose postulated existence they substantiated. To frame these developmental antecedents theoretically, consider that imitation, which lies at the heart of zygonic theory, can only have significance in the context of potential variety. This is because for one sound (or 
aspect of sound) to be heard as deriving from another - for the concept of agency in repetition to exist - requires a (hypothetical) range of options to be available. That is to say, before children can appreciate or make imitatively generated patterns in sound, they need to be able to process or create a range of sonic alternatives. This in turns implies that they will have had many, diverse listening experiences and sound-making opportunities. Examples of children functioning at this level who were observed in the course of the Sounds of Intent project include Rick, whose 'eye movements intensify when he hears the big band play' and Oliver, who 'scratches the tambourine, making a range of sounds ... whenever he plays near the rim and the bells jingle, he smiles' (Ockelford, et al., 2011, pp. 179 and 180).

A few of the children who were involved in the Sounds of Intent research appeared to be at a stage before this one of developing auditory perception, when the processing of sound had yet to get underway at all. Examples included Anna, who

sits motionless in her chair. Her teacher approaches and plays a cymbal with a soft beater, gently at first, and then more loudly, in front of her and then near to each ear. She does not appear to react.

and Yerik, who

usually makes a rasping sound as he breathes. He seems to be unaware of what he is doing, and the rasping persists, irrespective of external stimulation. His class teacher has tried to see whether Yerik can be made aware of his sounds by making them louder (using a microphone, amplifier and speakers), but so far this approach has met with no response.

(Ockelford, 2012, p. 129).

It seemed that nothing could precede this pre-perceptual stage, so it was termed (Sounds of Intent) Level 1. The pre-structural stage, referred to above, of which Rick and Oliver provided examples, was called Level 2. The three stages of structural cognition, pertaining to events, groups and frameworks, were designated respectively Levels 3, 4 and 5. These five levels, while covering a vast range of musical development, did not seem to present a complete picture, however, as there were examples of children engaging with music who were more or less consciously manipulating the parameters of sound - pitch, timing, loudness and timbre - to achieve particular expressive ends. For instance, Ciara 
who is a good vocalist despite having severe learning difficulties, is learning how to convey a range of different emotions in her singing through using techniques such as vibrato, rubato, consciously using a wider range of dynamics, and producing darker and lighter sounds.

And Ruth,

who sings well, and is used to performing in public, although she has severe learning difficulties and autism. She can learn new songs just by listening to her teacher (who is not a trained singer) run through them, and as she gets to know a piece, she intuitively adds expression as she feels appropriate. ... Later, when she listens to other people singing the songs she knows, she clearly prefers some performances to others. Her teacher believes this shows that she has a mature engagement with pieces in mid-to-late twentieth-century popular style.

(Ockelford, 2012, p. 129).

This stage of musical development, in which young people appeared to be aware of the culturally determined rules of expressive performance, was labelled Level 6.

The six Sounds of Intent levels, and the core cognitive abilities associated with each, can be summarised as follows (Ockelford, 2012, p. 148). See Table 1.

\begin{tabular}{|c|c|c|c|}
\hline Level & Description & Acronym & Core cognitive abilities \\
\hline 1 & Confusion and $\underline{\text { Chaos }}$ & $\mathrm{C}$ & No awareness of sound \\
\hline 2 & Awareness and Intentionality & $\mathrm{I}$ & $\begin{array}{r}\text { An emerging awareness of sound and of the variety that is possible } \\
\text { within the domain of sound }\end{array}$ \\
\hline 3 & Relationships, repetition $\underline{\text { Regularity }}$ & $\mathrm{R}$ & $\begin{array}{r}\text { A growing awareness of the possibility and significance of relationships } \\
\text { between sonic events }\end{array}$ \\
\hline 5 & Sounds forming $\underline{\text { Clusters }}$ & $\mathrm{C}$ & $\begin{array}{r}\text { An evolving perception of groups of sounds and of the relationships that } \\
\text { may exist between them }\end{array}$ \\
\hline 6 & Deeper structural Links & $\mathrm{L}$ & $\begin{array}{c}\text { A growing recognition of whole pieces, and of the frameworks of pitch } \\
\text { and perceived time that lie behind them }\end{array}$ \\
\hline
\end{tabular}

Table 1 The six levels underpinning the Sounds of Intent framework (acronym 'CIRCLE').

The Sounds of Intent research further divided the universe of potential musical engagement into three domains: 'reactive' ('R'), which entailed listening and responding to sounds; 'proactive' ('P'), which involved causing, creating or controlling sounds; and 'interactive' (' $\mathrm{I}$ '), which meant 
participating in sound-making activity in the context of others. Conceptually, the three domains and six levels were orthogonal, implying that they could be represented as a matrix with 18 cells. This was represented visually as a series of concentric circles divided into segments, ranging from the centre (Level 1), with its focus on self, to the outermost ring (Level 6), with its reference to wider communities of others. The convention of denoting each segment by its domain (R, P or I) followed by its level (1, 2, 3, 4, 5 or 6) was used. Hence 'R.1' refers to 'Reactive Level 1', 'P.3' to 'Proactive Level 3', and 'I.6' to 'Interactive Level 6'. Brief descriptors were developed for the segments, which sought to summarise the nature of the musical engagement that each involved. See Figure 10.

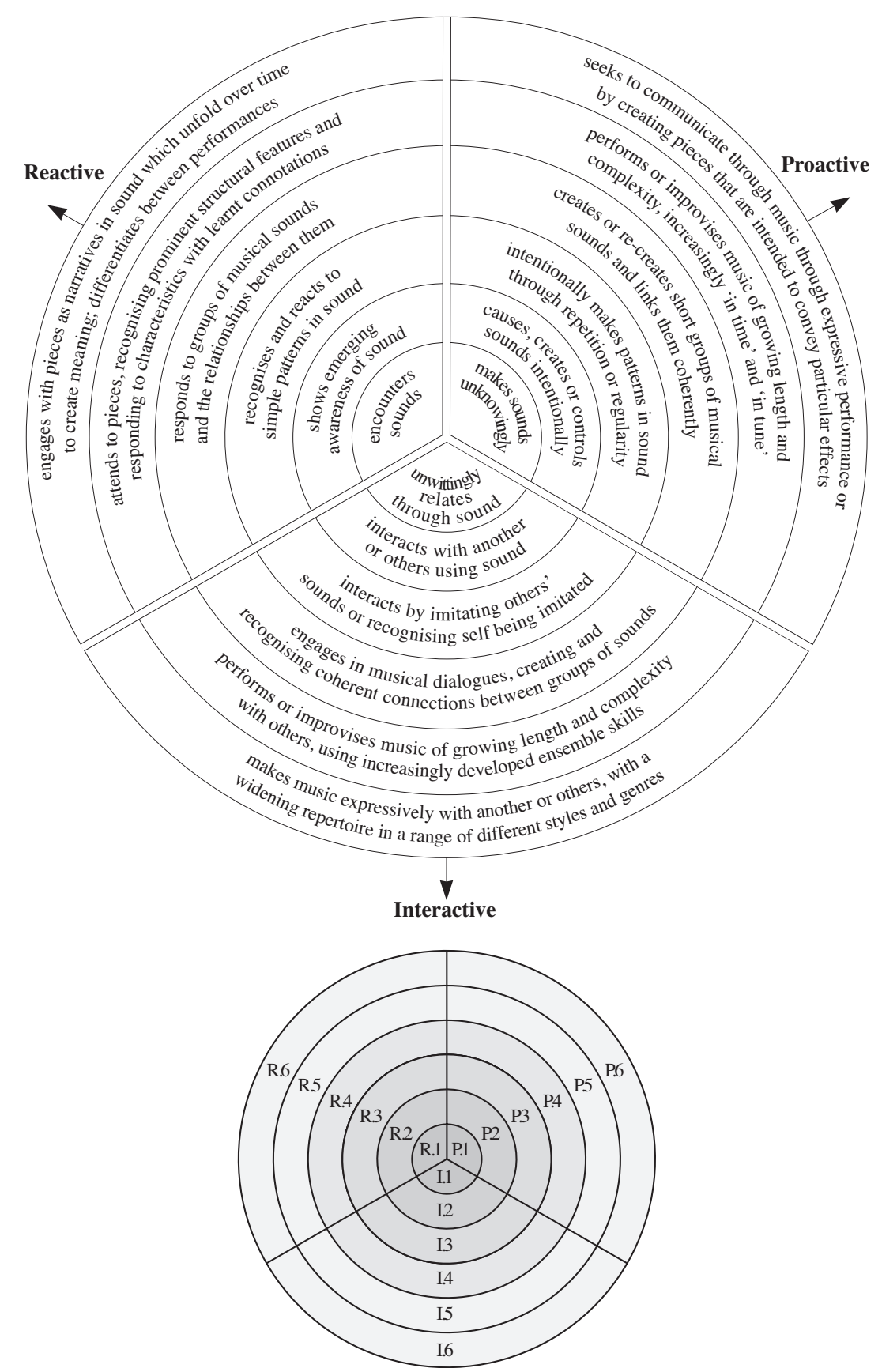


Figure 10 Visual representation of the Sounds of Intent framework.

Implications of the Sounds of Intent music-developmental model for our understanding of the evolving sense of self in children with learning difficulties

Ockelford and Welch (2012) and Ockelford and Vorhaus (2015) explored the connection between the music-developmental levels identified in the Sounds of Intent framework and the evolving sense of self found in children with learning difficulties. To do this, the Sounds of Intent levels were matched to an extended version of the model of early expressive communication set out in Ockelford (2002). The result is shown in Table 2.

\begin{tabular}{|c|c|c|c|}
\hline $\begin{array}{c}\text { Phase of } \\
\text { expressive } \\
\text { communication }\end{array}$ & $\begin{array}{l}\text { Vocal / verbal } \\
\text { level of } \\
\text { development }\end{array}$ & $\begin{array}{l}\text { Corresponding } \\
\text { Sounds of Intent } \\
\text { proactive levels }\end{array}$ & $\begin{array}{l}\text { Corresponding } \\
\text { Sounds of Intent } \\
\text { interactive levels }\end{array}$ \\
\hline non-intentional & $\begin{array}{l}\text { cries in response } \\
\text { to need }\end{array}$ & $\begin{array}{c}\text { P.1 } \\
\text { makes sounds unknowingly }\end{array}$ & $\begin{array}{c}\text { I.1 } \\
\text { unwittingly relates through sound }\end{array}$ \\
\hline intentional & $\begin{array}{l}\text { deliberately vocalises } \\
\text { to show need }\end{array}$ & $\begin{array}{c}\text { P.2 } \\
\text { causes, creates or controls sound } \\
\text { intentionally }\end{array}$ & $\begin{array}{c}\text { I.2 } \\
\text { interacts with another or others } \\
\text { using sound }\end{array}$ \\
\hline & makes personal & $\begin{array}{c}\text { P.3 } \\
\text { intentionally makes patterns in sound } \\
\text { through repetition or regularity }\end{array}$ & $\begin{array}{c}\text { I.3 } \\
\text { interacts by imitating other's sounds } \\
\text { or recognising self being imitated }\end{array}$ \\
\hline symbolic & $\begin{array}{l}\text { utterances: } \\
\text { for example, says } \\
\text { 'mmm' meaning } \\
\text { 'hair dryer' }\end{array}$ & $\begin{array}{c}\text { P.4 } \\
\text { creates or re-creates short groups of } \\
\text { musical sounds and links them coherently }\end{array}$ & $\begin{array}{c}\text { I.4 } \\
\text { engages in musical dialogues, } \\
\text { creating and recognising coherent } \\
\text { connections between groups of } \\
\text { sounds }\end{array}$ \\
\hline formal & speaks (using words) & $\begin{array}{c}\text { P.5 } \\
\text { performs or improvises music of growing } \\
\text { length and complexity, increasingly 'in } \\
\text { time' and 'in tune' }\end{array}$ & $\begin{array}{l}\text { I.5 } \\
\text { performs or improvises music of } \\
\text { growing length and complexity with } \\
\text { others, using increasingly developed } \\
\text { ensemble skills }\end{array}$ \\
\hline pragmatic & $\begin{array}{l}\text { uses language with } \\
\text { appropriate social } \\
\text { understanding }\end{array}$ & $\begin{array}{l}\text { P.6 } \\
\text { seeks to communicate through music } \\
\text { through expressive performance or by } \\
\text { creating pieces that are intended to } \\
\text { convey particular effects }\end{array}$ & $\begin{array}{c}\text { I.6 } \\
\text { makes music expressively with } \\
\text { another or others, with a widening } \\
\text { repertoire in a range of different } \\
\text { styles and genres }\end{array}$ \\
\hline
\end{tabular}

Table 2 The Sounds of Intent levels mapped onto the developmental stages of expressive communication.

This composite developmental map was aligned with the notion of an evolving self through reference to Shaun Gallagher's distinction between the minimal self, considered as 'a consciousness of oneself as an immediate subject of experience, unextended in time', and the narrative self, considered as 'self-image that is constituted with a past and a future in the various stories that we and others tell about ourselves' (Gallagher, 2000, p. 15). The outcome is shown in Figure 11. 


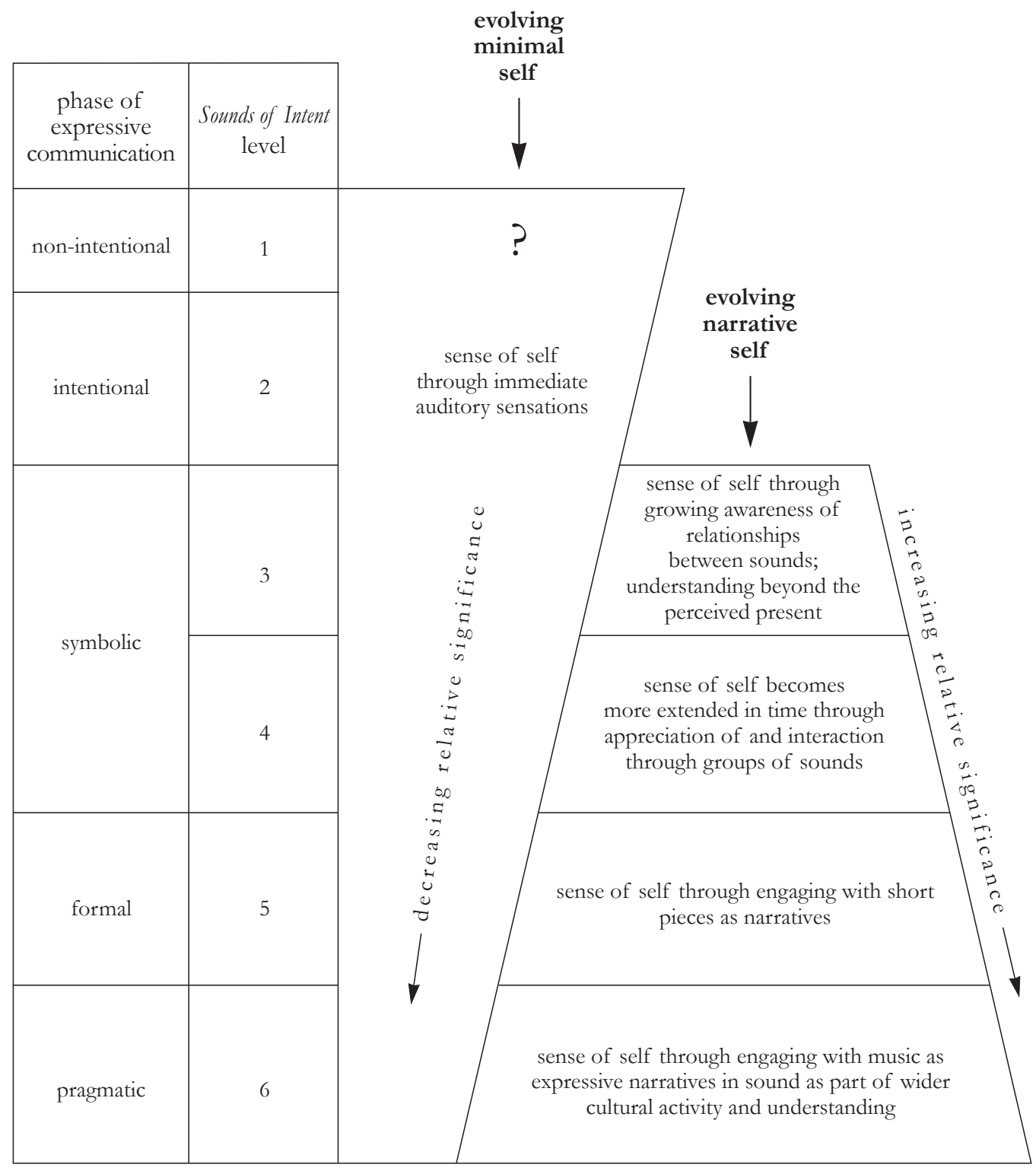

Figure 11 Putative parallels between stages of musical development and an evolving sense of self.

The discussion that follows extends this thinking (which conceives of musical engagement as a proxy indicator of a sense of self): conceptualising musical reactivity, proactivity and interactivity at different development levels as a window onto the evolving empathetic mind of children with learning difficulties and autism. To this end, we present six vignettes of musical engagement at each of the six Sounds of Intent levels, with reflections on each of these in terms of their implications for the children's awareness of and sensitivity to others' musical thinking and feeling, and for our understanding of musical empathy more generally. 


\section{Six vignettes}

1. Amelia

A teaching assistant pushes Amelia in her wheelchair into the music room to join her class for their weekly session with the music therapist. All six children in the group, who are 13 or 14 years of age, have profound and multiple learning difficulties, meaning that they are in the very early stages of cognitive, emotional and social development. In previous sessions, the therapist has been unable to discern any response from Amelia to the wide range of musical sounds particularly vocal sounds - that have been presented. And today is the same: Amelia reclines motionless in her chair, gaze fixed, apparently not making sense of visual stimuli. She makes no discernible response to any of the sounds that are presented, nor any observable attempt to make sound deliberately with her voice or by moving her fingers against a lightweight wind chime that is placed next to her hand. Although she sometimes wheezes as she exhales, the therapist's efforts to make Amelia aware of this by using a microphone and amplification system do not elicit a response or change in her breathing pattern. Amelia makes no noticeable attempts to interact with her assistant who, as the session progresses, sensitively tries to engage her through touch, sight and sound, emulating and complementing the breathy sounds that Amelia makes.

Amelia appears to be oblivious to the sounds around her (and of stimuli in other sensory domains), and she seems to be unaware of her capacity to make noises as a product of her own bodily functions such as breathing. Inevitably, then, she is unable to interact knowingly through sound. Hence we can assume that she is functioning at Sounds of Intent Level 1. What does this mean in terms of empathy? As have seen, according to Meltzoff, having a sense of other requires first a sense of self. Yet there are no indications that Amelia has reached this stage of awareness, let alone a notion of self and other. Hence we must conclude that she is not yet capable of experiencing musical empathy, either affectively or cognitively (see Figures 12 and 13). The music therapist, however, intuitively interprets Amelia's sounds in the context of communication, and responses are musically empathetic. The teaching assistant too, by responding sensitively to Amelia's sounds is exhibiting musical empathy, or, as Cross, Laurence and Rabinowitch (2012) would have it, being 'creatively empathic'. 


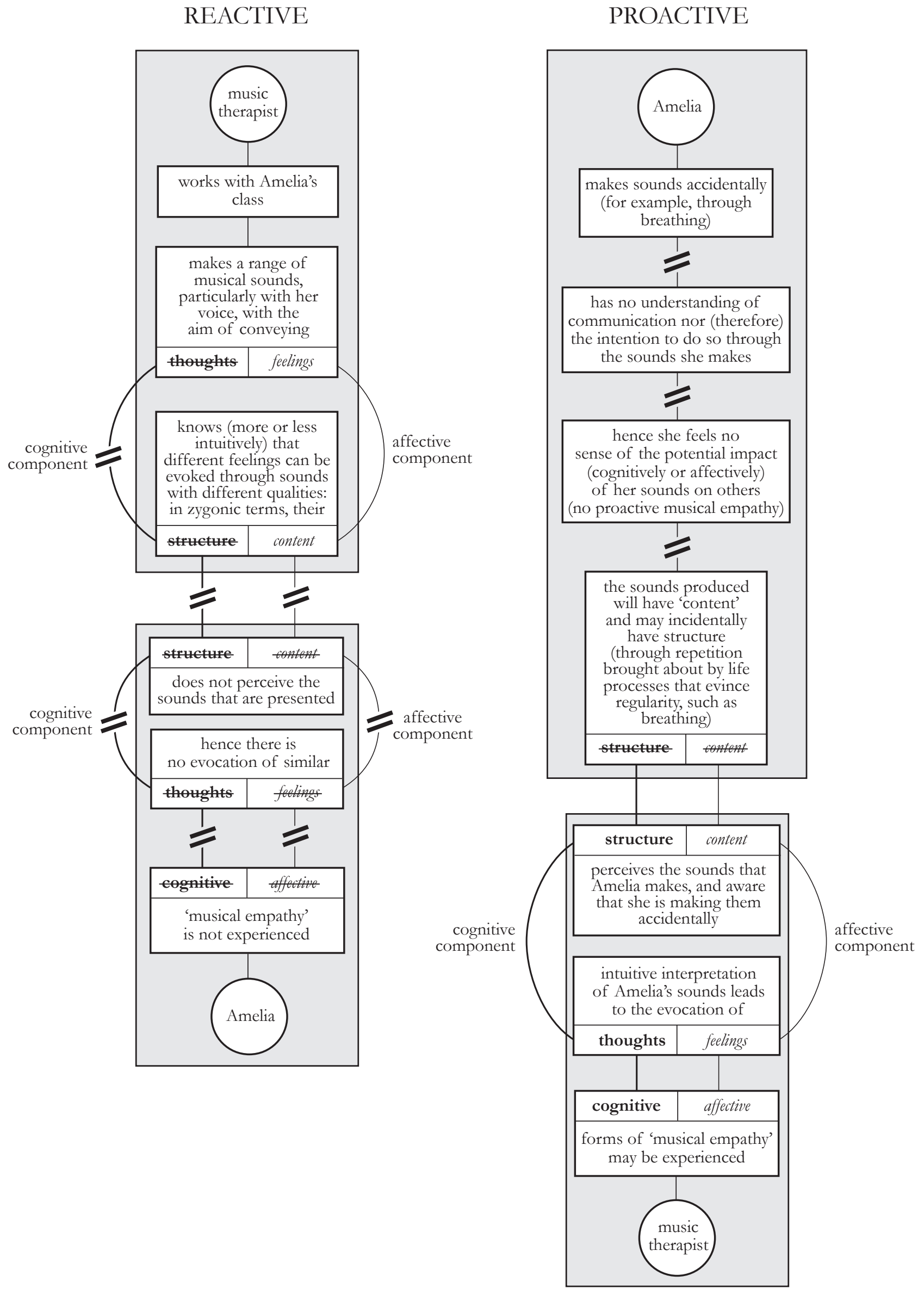

Figure 12 Amelia shows no signs of reactive or proactive musical empathy (Level 1). 


\section{INTERACTIVE}

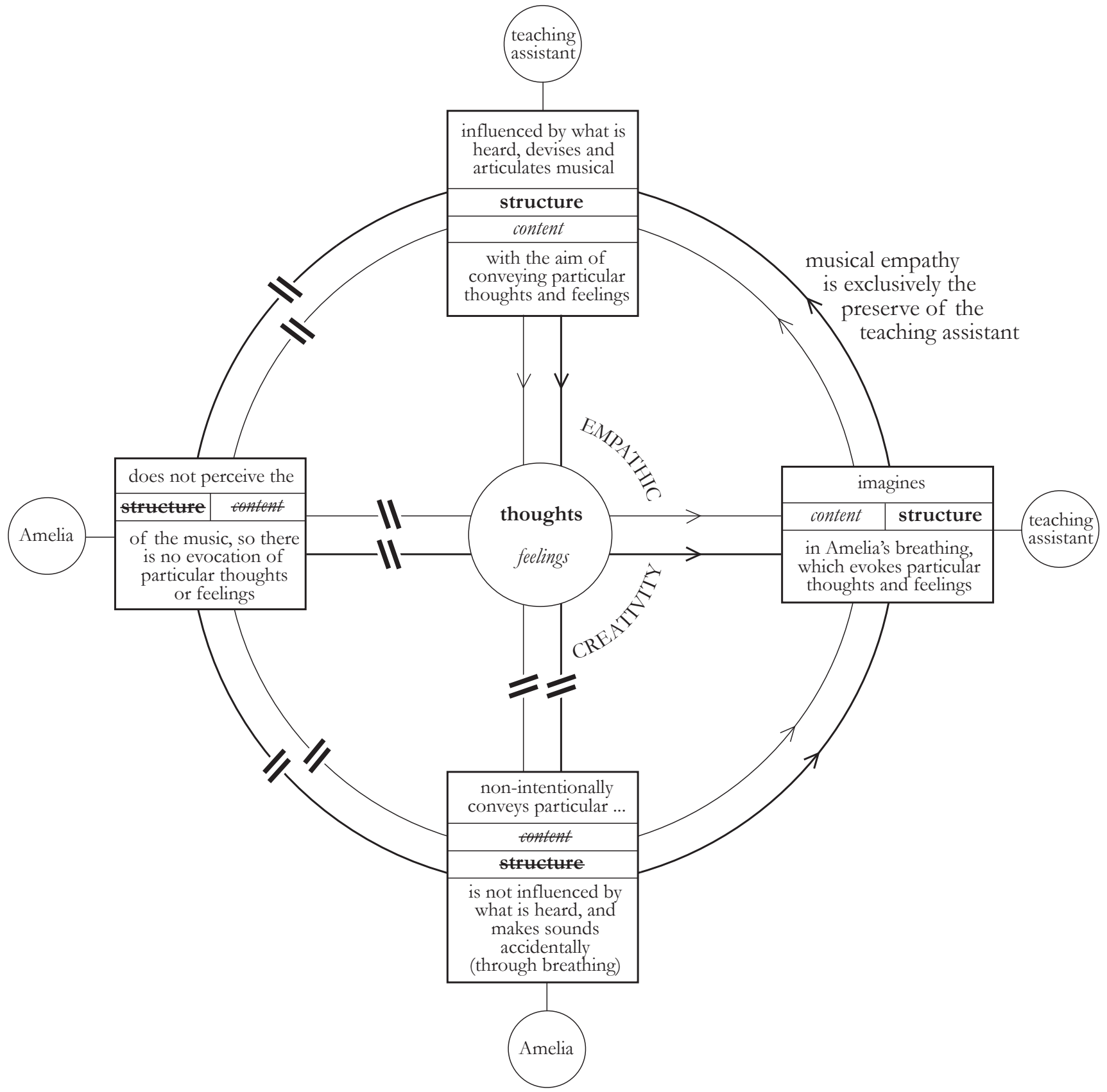

Figure 13 Amelia shows no signs of interactive musical empathy (Level 1).

\section{Ethan}

Ethan is six. He has profound global developmental delay, and he functions in many ways as though he were around four or five months old. His mother notices that he is becoming more aware of the sounds around him, and he appears to respond in particular to the female human voice, sometimes picking up on the emotions that are expressed. He tends to find it upsetting when he hears someone cry, for example - particularly other children, such as his baby brother and will occasionally smile when others laugh. Ethan can himself make a range of vocal sounds, 
which he uses to express how he is feeling: happy, sad, excited, frustrated, angry or quietly content. He is beginning to realise that his vocalisations can have an effect on other people, and when he sees someone he knows, he will often try to engage them through making a sound, and waiting for a response. He will also vocalise when people speak or sing to him, though there is no evidence of deliberate imitation on his part.

This account of Ethan suggests that he has an emerging awareness of sound and of the variety that is possible within the auditory domain. He has a sense of his own capacity to make a range of sounds, and interacts through sound with other people. Hence it is reasonable to assert that he is functioning at Sounds of Intent Level 2. In terms of the development of musical empathy, we can assume that Ethan's sense of agency, derived from his ability to create sound, and his capacity to externalise his feelings through sound, must contribute to an evolving sense of selfof his own identity in relation to others. This is shown by his realising that he can affect others through his sound-making, and his desire for other people to reciprocate when he vocalises. His sense of other is evident too in the emotional contagion he experiences when those around him cry or laugh. By having the capacity to be stimulated through sounds expressive of emotion to feel what others feel (rather as newborns do - see Simner, 1971; Sagi and Hoffman, 1976; Martin and Clark, 1982), and despite (presumably) being unable to reflect on this process, it seems reasonable nonetheless to assert that Ethan is capable of experiencing a basic form of affective (though not yet cognitive) empathy in the domain of sound (Zahn-Waxler and RadkeYarrow, 1990; McDonald and Messinger, 2011). Strictly speaking, this cannot be considered to be 'musical empathy', since, according to zygonic theory, the characteristic that distinguishes music from other forms of sound (such as speech and everyday noise) is the presence of repetition deemed to be brought about through imitation. Hence a more accurate term might be 'proto-musical empathy' - see Figures 14 and 15. 
REACTIVE

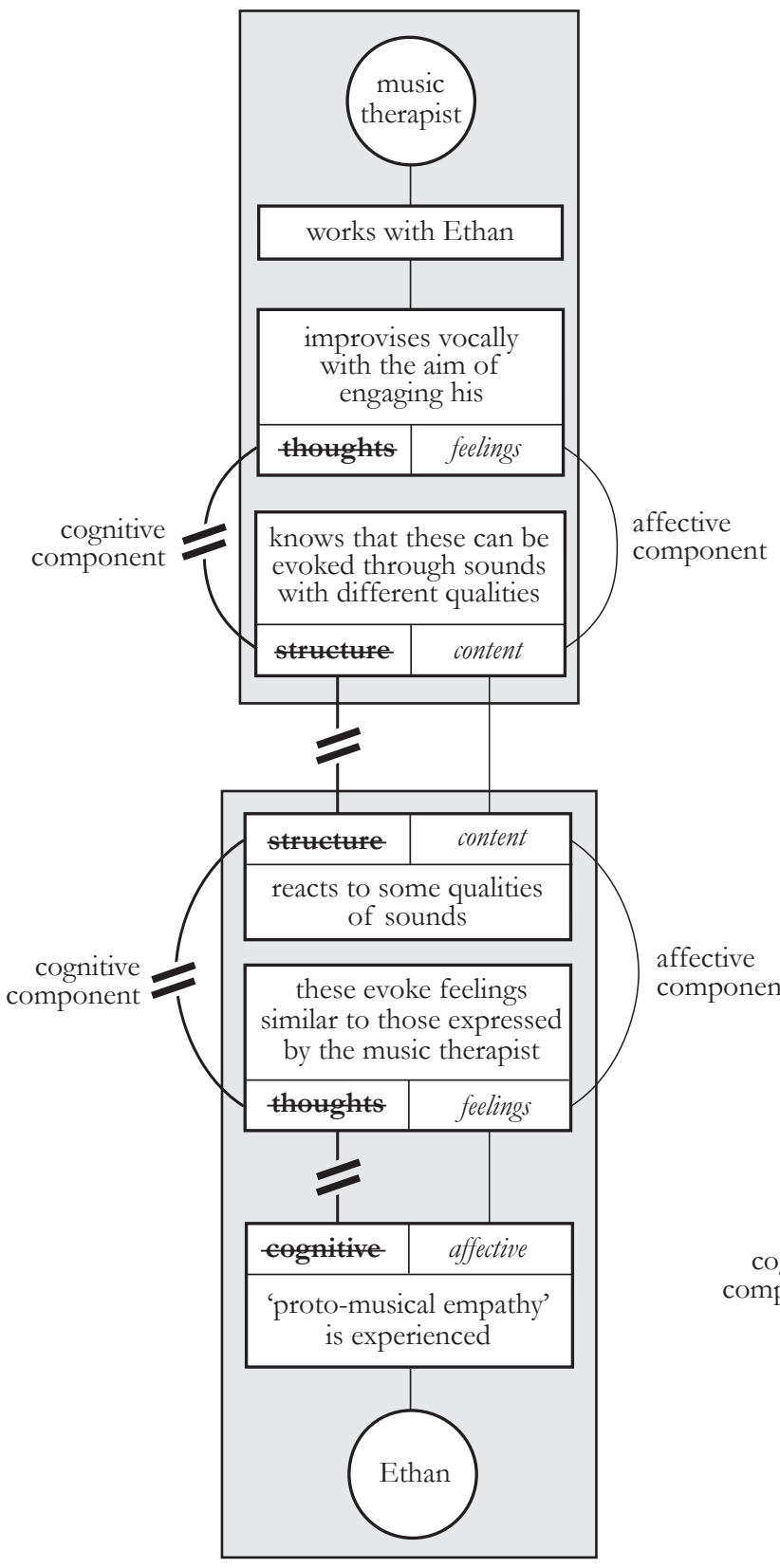

PROACTIVE

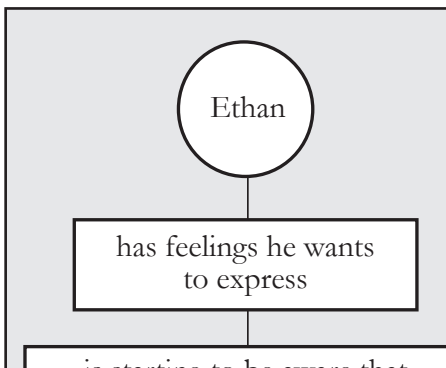

is starting to be aware that the vocal sounds he makes can have an impact on those around, and that the impact varies according to the nature of sounds ('proto-musical empathy')

sometimes vocalises with the intention of communicating with other people

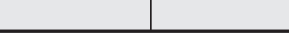

the sounds produced will have 'content' and may incidentally have structure (through muscular repetition)

\begin{tabular}{l|l} 
structure & content \\
\hline
\end{tabular}

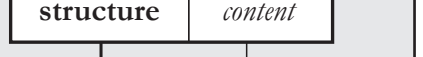

nent

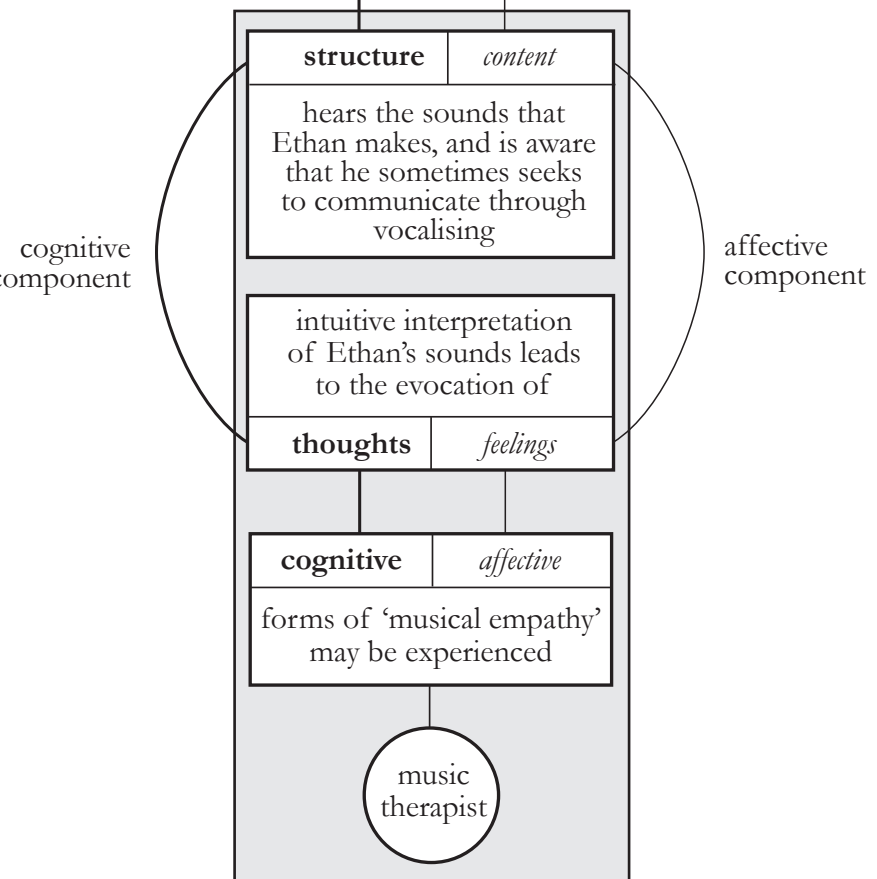

Figure 14 Ethan shows signs of reactive and proactive proto-musical empathy (Level 2). 
INTERACTIVE

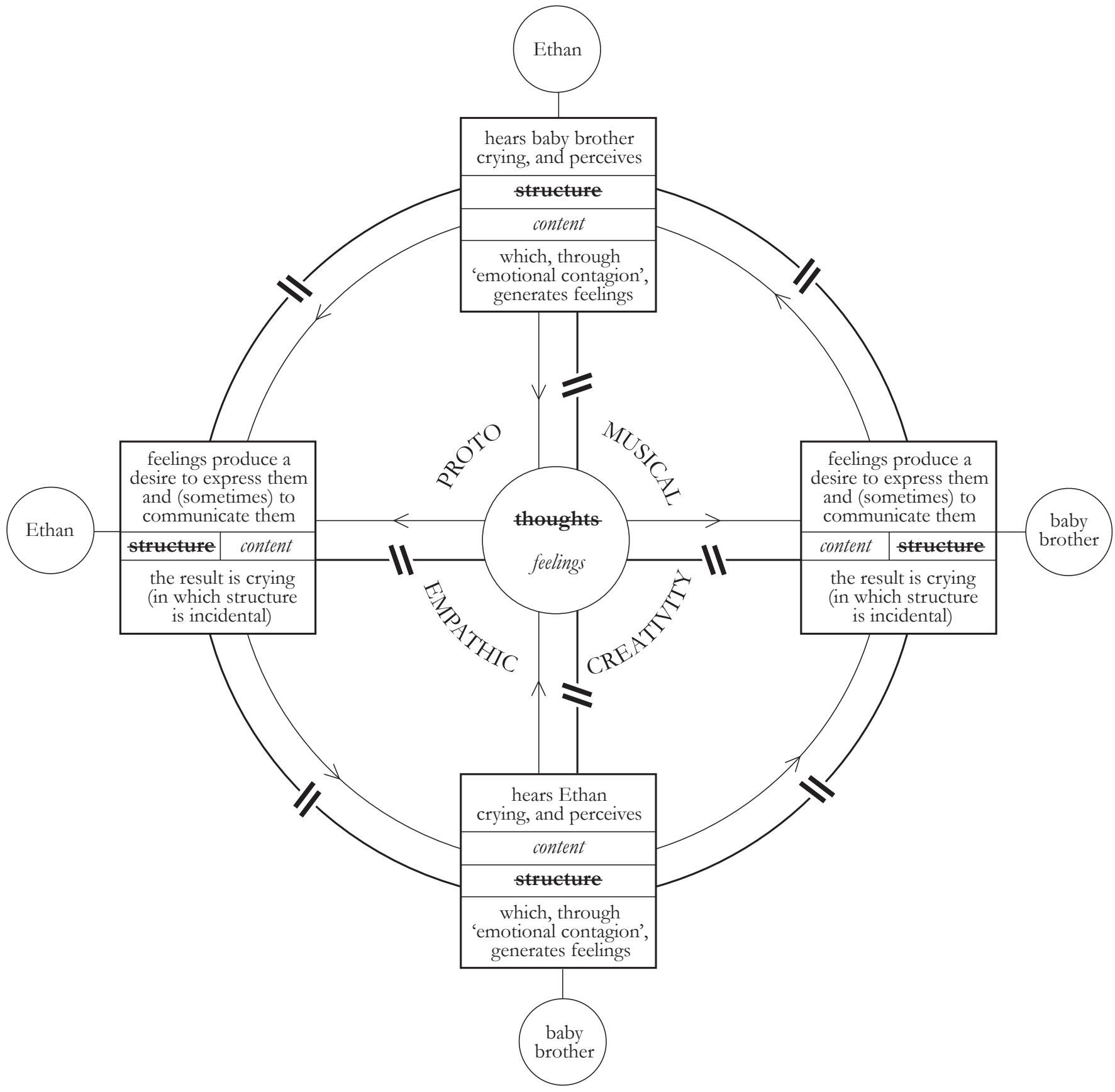

Figure 15 Ethan shows signs of interactive proto-musical 'empathic creativity' (Level 2).

\section{Chloe}

Chloe has severe learning difficulties. She is eight years old. She has a vocabulary of around 10 words that she uses to communicate some of her basic needs, and, beyond this, her family and the staff at her school have learnt to interpret a range of idiosyncratic gestures that she makes, such as flapping her hand for 'more'. In day-to-day life, Chloe gives little or no sense of being aware of, or concerned about, other people's circumstances, thoughts or feelings. However, she loves it when people copy the sounds that she produces - when they do it makes her laugh - and 
she never seems to get bored, flapping her hand enthusiastically. Sometimes she tries to copy other people too, especially the funny sounds that they make with their voices, and she can become excited when she gets it right. Chloe also likes banging things loudly on hard surfaces (such as her kitchen table at home or the wooden floor in her classroom), using anything she has to hand, making regular beats that go on and on, and if her class teacher starts clapping or tapping a steady pulse, she can anticipate what comes next and join in. The nature of the sound that is made seems less important to Chloe than the regularity of the beat. She also enjoys listening to any pieces with a strong rhythmic drive - especially the relentless uniformity of dance music.

It seems that Chloe appreciates simple patterns of repetition and imitation in sound, in relation to listening, to her own production and through interaction with other people. Hence she appears to be functioning at Sounds of Intent Level 3, which has a number of implications for her capacity to think and feel music-empathetically. For instance, her ability to copy some of the sounds that other people make (and the pleasure that she takes in doing so) suggests that she has some sense of 'being like them' (Meltzoff, 2005). Moreover, that fact that she is aware of being imitated means that she may have a notion, at some level, of those people 'being like her'. (See Figure 16.) Hence, in Meltzoff's terms, Chloe intuitively knows that there is someone else out there who is 'like her but isn't her' - the first step towards her having a fully-fledged theory of mind. Beyond this, since Chloe can sustain a regular beat, which requires both memory and anticipation, we can surmise that (albeit non-consciously) her sense of self, in the form of her thoughts and feelings expressed in sound, extends from the perceived present into the recent past and the immediate future. Furthermore, her capacity to continue simple patterns started by others shows that she has moved beyond reacting to what they think and do to predicting their thoughts and actions: a further development in her evolving theory of mind (Figure 17). The fact that it is the regularity of the beat that is made (as opposed to the nature of its constituent sounds) suggests that musical structure is more significant to her than content - in empathetic terms, that thoughts are more important than feelings, that cognition is of more consequence than affect. 
REACTIVE

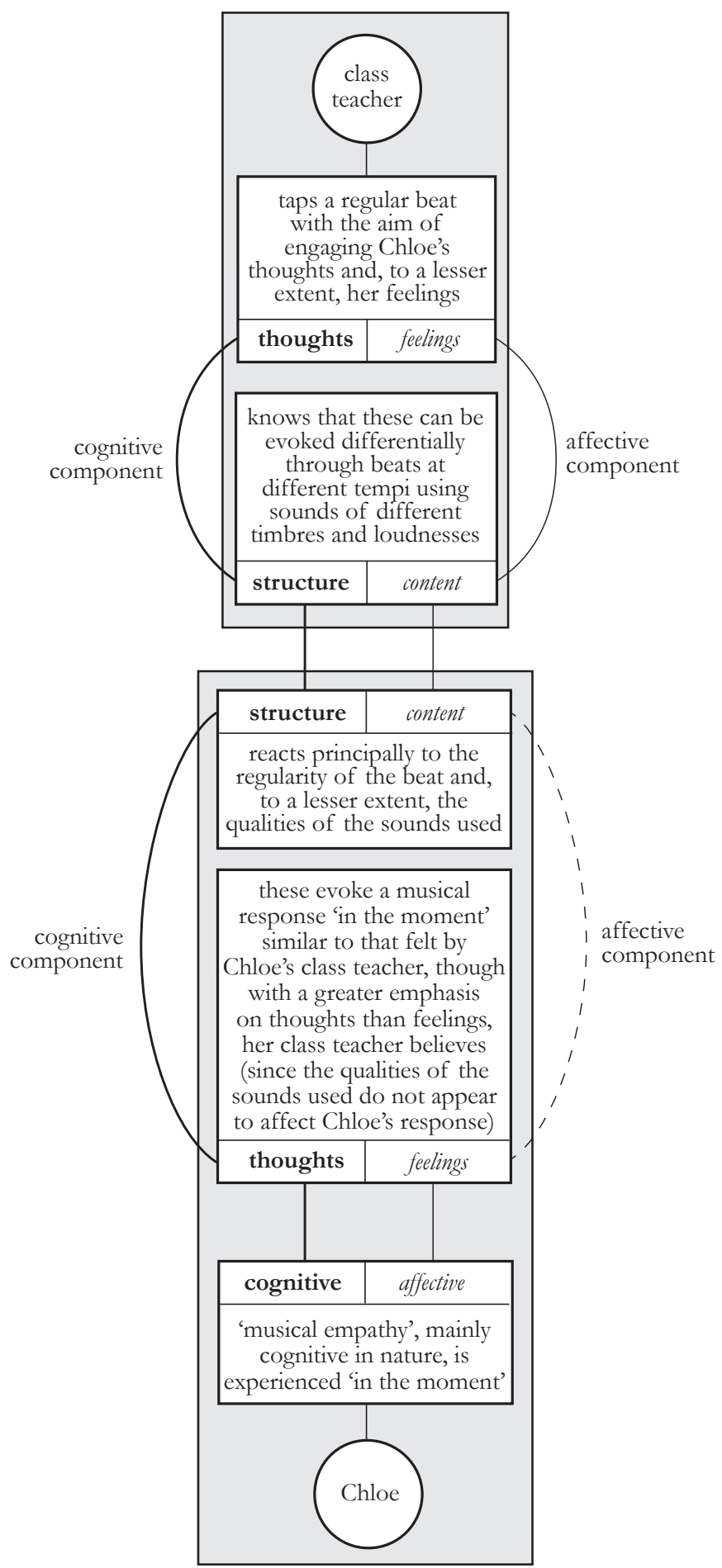

PROACTIVE

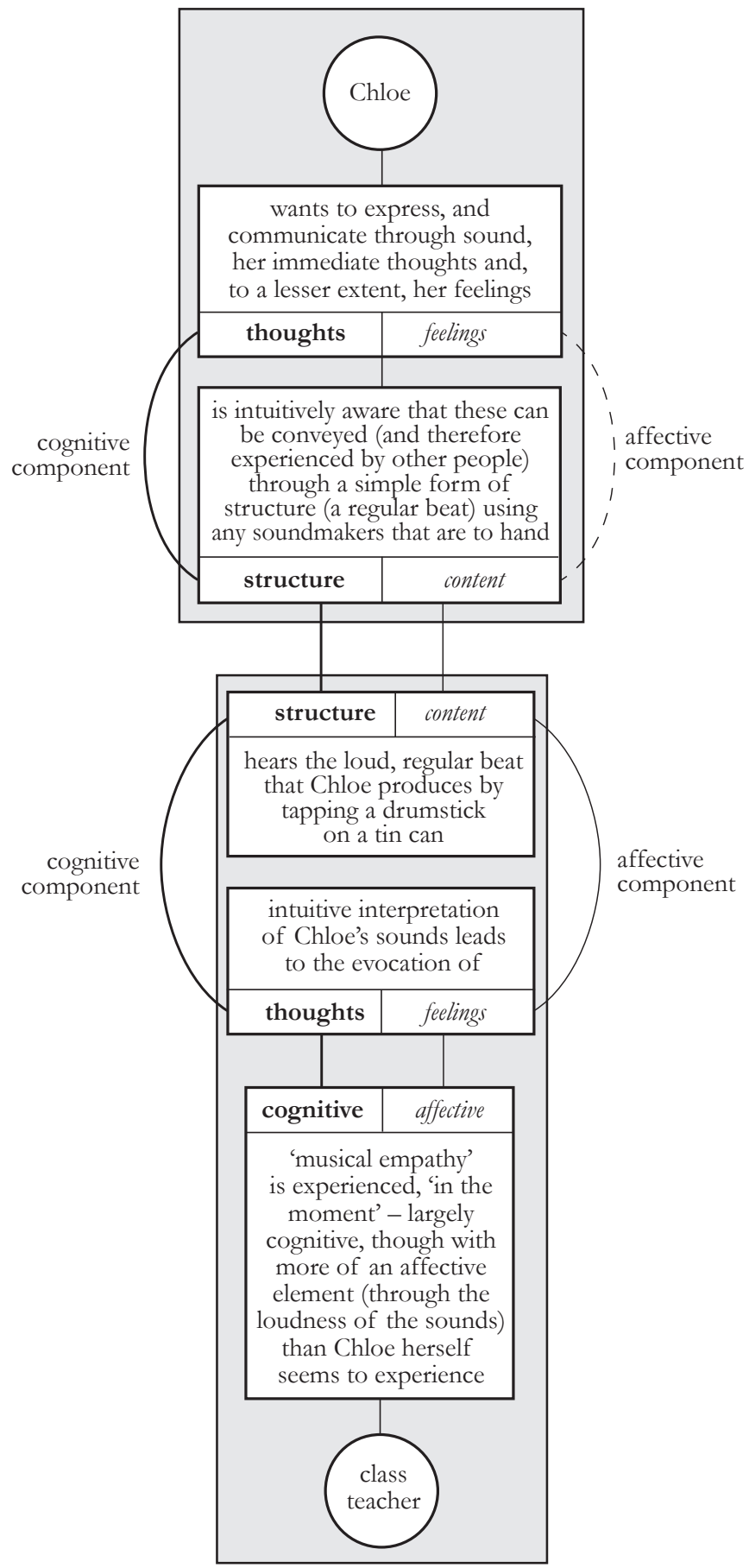

Figure 16 Chloe shows reactive and proactive musical empathy in the moment (Level 3). 


\section{INTERACTIVE}

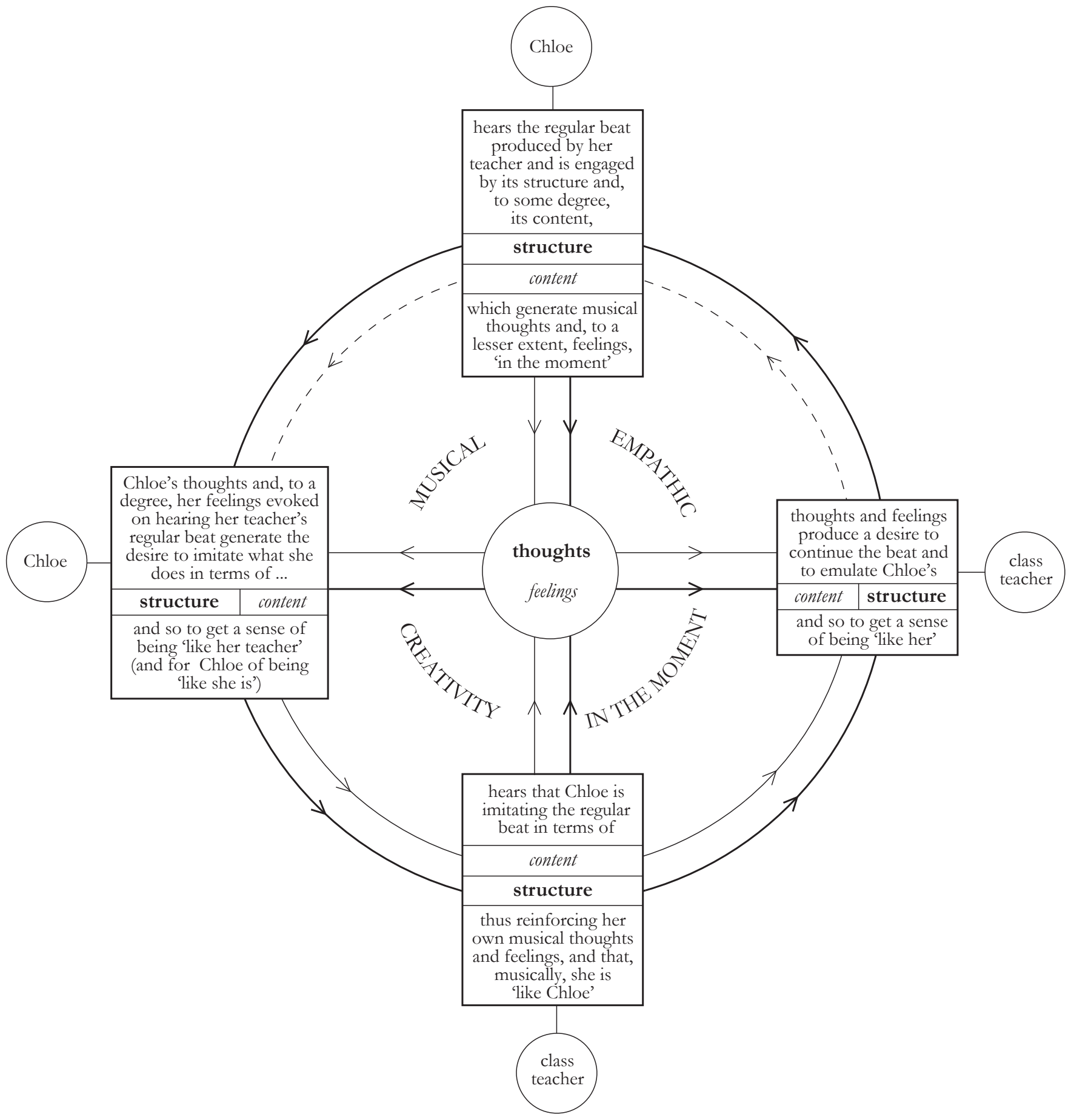

Figure 17 Chloe and her class teacher share musical empathic creativity in the moment through playing a common regular beat: 'she is like me' and 'I am like her' (Level 3).

\section{Drew}

Drew is 14 . He has severe learning difficulties, and functions in many ways at an early years level. He can communicate effectively, if idiosyncratically, using his vocabulary of around 100 words, which he tends to combine in short bursts of meaningful speech when he is motivated to do so. 
He likes noodling on the keyboard, playing scraps of tunes that he has heard - often the short 'hooks' from pop songs, some of which he appears to like partly through their association with his father, who plays in a band. He will repeat simple jazz riffs too, apparently relishing the fact that he can create an ongoing stream of sound. Although processing and producing verbal language appears to be something of an effort for Drew, he relaxes and evidently enjoys it when his music teacher sits down with him at the keyboard, and the two of them have extended conversations in sound, using short bursts of melodic material, sometimes copying exactly what the other has just done, and sometimes engaging in 'call and response' patterns, where ideas are changed as they bounce back and forth. During these interactions, Drew makes frequent eye contact with his teacher, and smiles from time to time, seeming to delight in the engagement with another person that music enables him to make.

Drew's preoccupation with 'chunks' of musical material suggests that he is functioning in music-developmental terms at Sounds of Intent Level 4. His capacity not only to repeat motifs but to develop them when interacting with his music teacher suggests, in terms of musical empathy, that he has moved beyond Meltzoff's notion of understanding that he is like his teacher yet not him' (Sounds of Intent Level 3) to acknowledging (albeit intuitively) that he is 'like his teacher yet different from him'. That is, although Drew's empathic capacity lies within a relatively narrow cognitive and affective range, his musical theory of mind appears to have developed to the point where he can grasp that another person's ideas about a fragment of music may be congruent with his own, yet distinct from it. There is a sense too that his appreciation of another's musical perspective extends beyond the immediate present (as experienced by Chloe), and that he recognises that other people's musical thinking may change over time: his music teacher does not always give the same response when Drew plays a particular riff, yet Drew is aware, at some level, that each of his teacher's distinct musical rejoinders arises from the same musical mind. The more extensive temporal envelope of conscious thought that is open to Drew (compared with Chloe) means that longer term memories can feature in his musicempathetic thoughts and feelings too: in particular, he is aware that the thinking and emotion that he associates with particular chunks of music may also be experienced by his music teacher. Yet outside the context of music-making, Drew struggles to get inside other people's heads; his language is too limited for him to convey or understand anything beyond information pertaining to his own immediate circumstances, needs or wants. Paradoxically, it is when he is freed from the constraints and frustrations of trying to use sounds with propositional meaning (words), and interacts instead using sounds with no symbolic meaning (notes), that Drew is able to glean insights into other people's minds - thoughts and feelings that the adults around him resort to describing with verbal language. 


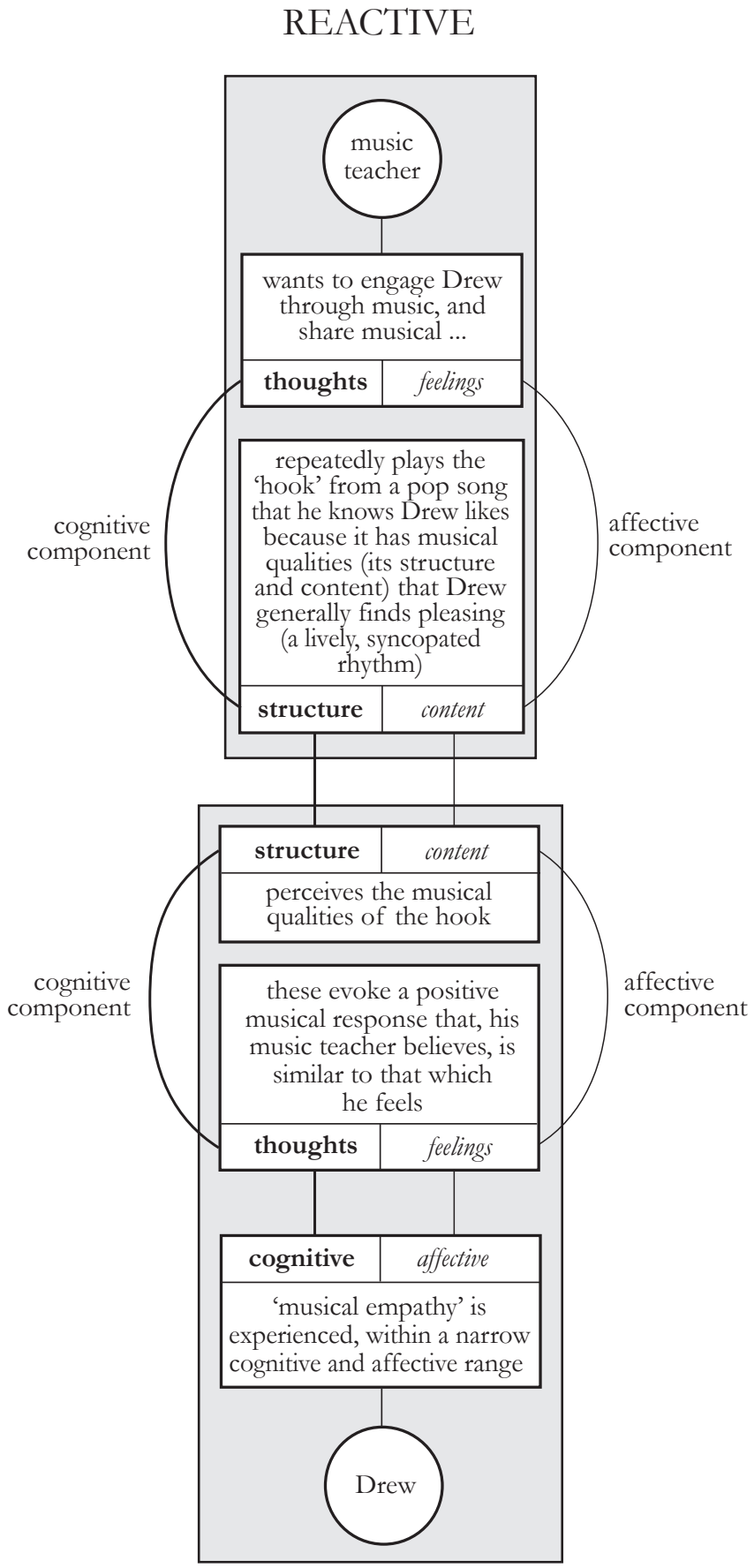

PROACTIVE

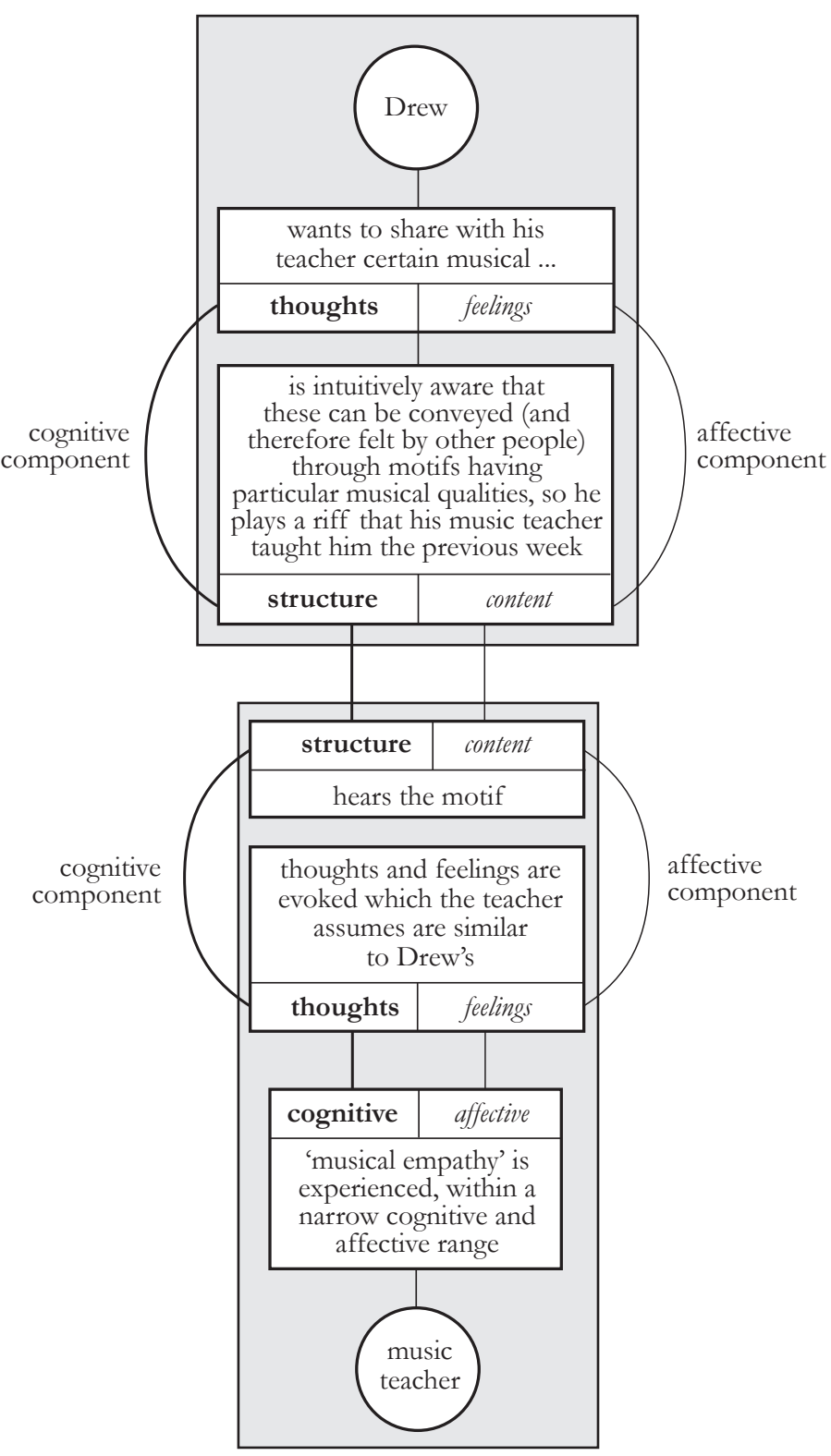

Figure 18 Drew shows reactive and proactive musical empathy through sharing a musical motif with his teacher, which has associative memories (Level 4). 


\section{INTERACTIVE}

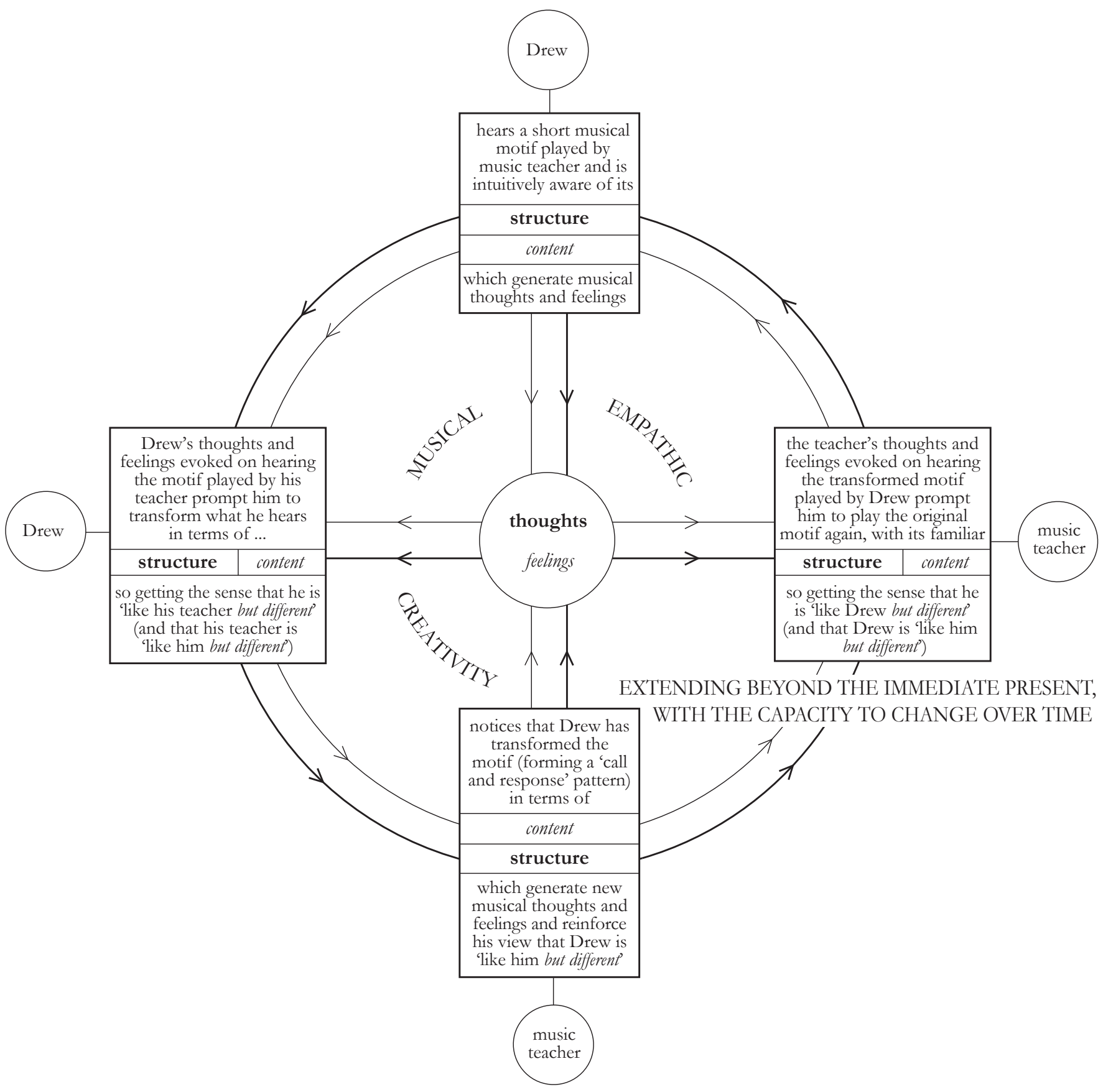

Figure 19 Drew and his music teacher share musical empathic creativity beyond the immediate present, that changes over time through a 'call and response' sequence using a short motif (Level 4).

\section{Freddie}

Freddie, nine years old, is on the autism spectrum and has severe learning difficulties. Although his receptive language enables him to glean, from what he is told, most of what is about to occur in everyday life, he rarely speaks, and when he does it is almost invariably to ask for something that he wants or to check what is going to happen next. Although Freddie is very affectionate and physically demonstrative with his family and the other familiar adults around him, his desire for 
human contact seems to driven more by hedonism than a concern for other's thoughts and feelings. He has a narrow range of interests, including music, in which domain he has exceptional talents (including absolute pitch) and is highly motivated, in a reactive way, spending a good deal of his leisure time listening to a wide range of music on his iPad - often the same piece over and over again. Proactively, however, he is rather more reluctant to engage in music making, and, despite having been learning the piano for around two years, he still usually displays an initial reluctance to get involved in lessons. Once he is over the participation threshold, though, he will sing and play with enthusiasm, often rocking vigorously to the beat. Freddie loves music that is, in every way, repetitive - the more highly structured the better, it seems - preferably with repeated notes, repeated phrases, and repeated sections, characteristic of such 1970s classics as Eye Level (popularly known as the Van der Valk TV theme) and Rockin' All Over the World (Status Quo), which he enjoys. He will improvise melodies over renditions of pieces that he knows, such as Twinkle, Twinkle, singing (wordlessly) or playing the keyboard. However, his productions of musical material, with or without other people, come across as having a 'mechanical' quality, which privileges repetition over change, precision over nuance - in the language of zygonic theory, structure over content.

In music-developmental terms, Freddie's capacity to improvise a tune over a familiar series of harmonies indicates that he has an intuitive grasp of typical Western intervallic and metrical frameworks (an ability that characterises of Sounds of Intent Level 5). With regard to musical empathy, Freddie has a somewhat lopsided profile in which the cognitive element is predominant. However, this is sufficient for him to have a sense of engaging with other people in a common musical purpose over time - sharing a given melodic and harmonic framework and producing either the same or complementary material. Hence we can surmise that Freddie is aware at some level that he and another person can experience periods of shared musical attention in which both parties make distinct contributions to a coherent musical whole; that is, someone else may have thoughts that differ from his yet are nonetheless congruent with them. This level of understanding appears to show that Freddie's capacity empathy in the domain of music is considerably more advanced than that available to him in everyday life. 
REACTIVE

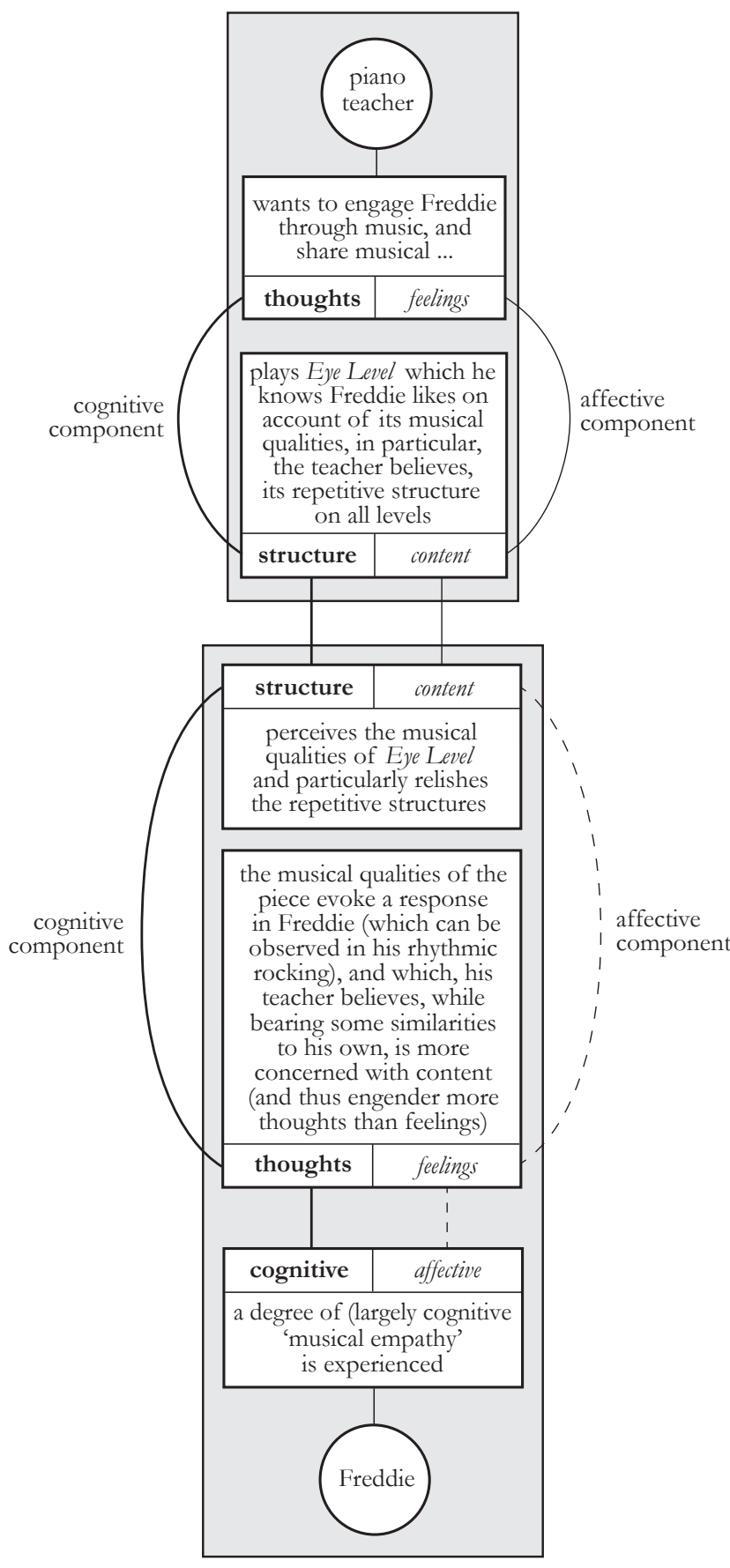

PROACTIVE

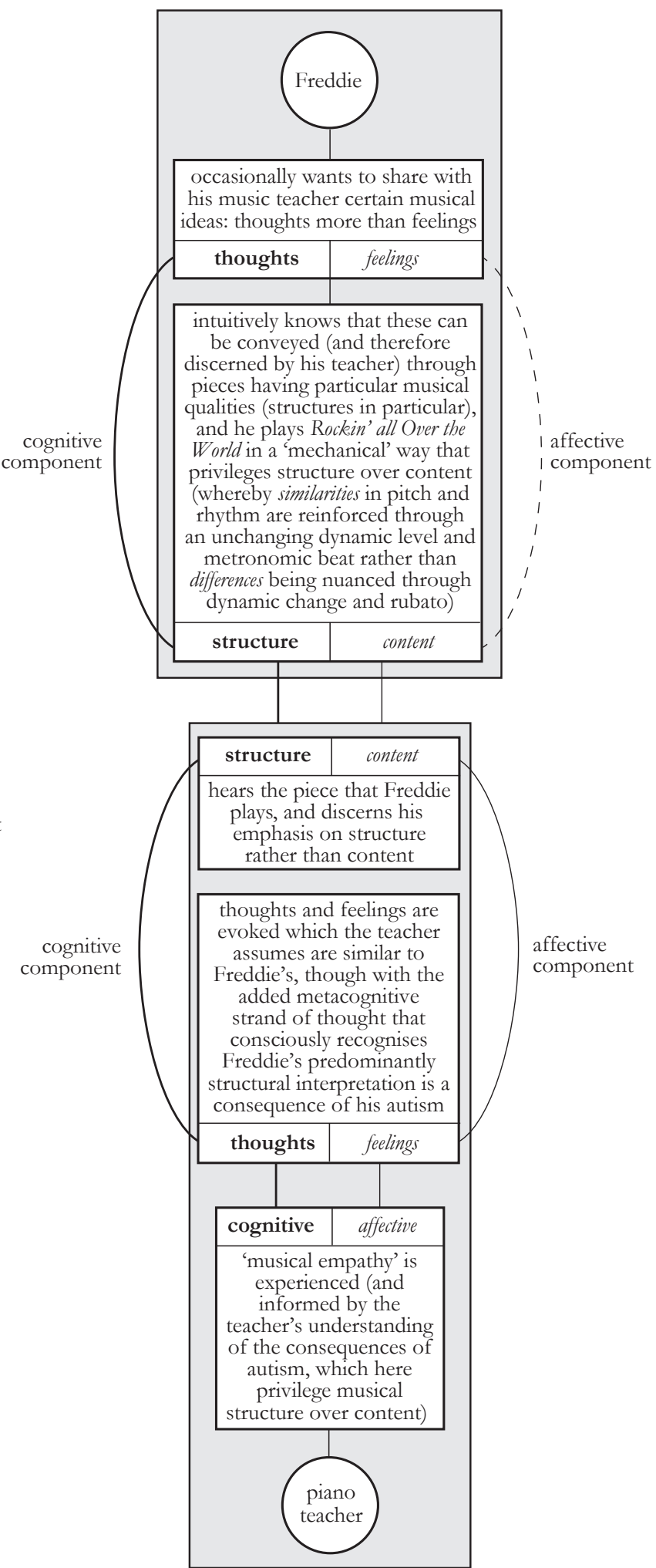

Figure 20 Freddie shows reactive and proactive musical empathy, which is largely cognitive in nature (Level 5), and reveals an asymmetrical pattern of empathy with his piano teacher (who appreciates Freddie's playing both cognitively and affectively). 
INTERACTIVE

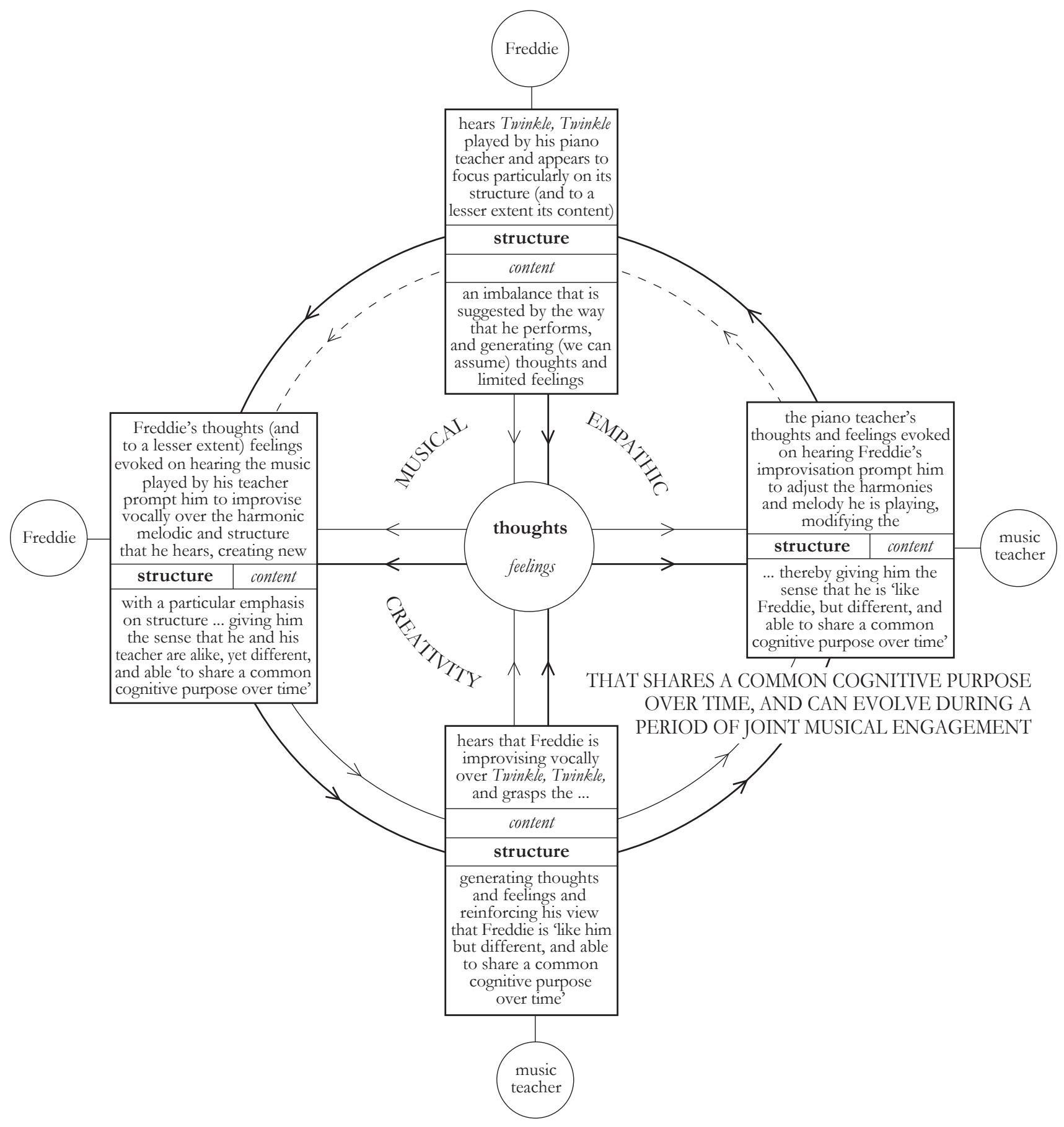

Figure 21 Freddie and his piano teacher share an asymmetrical musical empathic creativity through engaging in a common cognitive purpose over time in the domain of music (Level 5).

\section{Romy}

As we noted above, Romy, aged 14, has a severe developmental delay and is unable to speak. She is also left hemiplegic. Romy has a diagnosis of autism, and seems to be largely unaware of (or at least unconcerned by) the thoughts or feelings of other people. Musically, though, she shows great sensitivity, and enjoys playing pieces - including, for example, Stevie Wonder's I Just Called 
to Say I Love You - in the form a melody and a rudimentary bass line (on account of the relative weakness of her left hand), articulating the structure and content using devices such as rubato and changes in dynamics, improvising fills, and delighting in the impact that her performance has on listeners in close proximity. Romy likes to be entertained too, and will listen intently to renditions of favourite works, such as Bach's little' Prelude in F, BWV 928, relishing the climaxes that are marked out with ritardandi and crescendi, jumping up, flapping her hands and sometimes shrieking with pleasure as a physical embodiment of the strong emotions that she feels. Interactively, in piano duets improvised on pieces such as the Cavatina from the film the Deer Hunter, Romy, playing the melody, will not only follow the tempo, articulation and dynamic contours that her co-performer offers, but she will also predict, with some accuracy, the expressive devices that her accompanist is likely to use. These include holding back the onsets of notes at the top of phrases, sometimes to an even greater extent than her fellow performer, and exaggerating the dynamics. Romy is increasing comfortable in interacting with a range of other musicians, and she seems to enjoy testing the limits of their capabilities (by deliberating changing key) and challenging their aesthetic sensibilities (by pushing the expressive envelope even further than usual).

Despite her technical limitations on the piano, Romy's expressive playing and her sophisticated interactions with other musicians suggest that she has a mature understanding of several styles of music within her culture, implying that she is functioning at Sounds of Intent Level 6. Of course, one could contend that Romy has merely learnt to emulate the elements of expressive performance without herself feeling the emotions of which they were originally an expression an argument that is occasionally levelled at musical savants such as Derek Paravicini (Ockelford, 2008). This line of reasoning can be difficult to counter since neither Romy nor, indeed, Derek are able to reflect verbally on their responses to music. However, the fact that Romy's feelings are embodied in movement and conveyed through screams of delight, and that these correspond to what would generally be acknowledged as emotional peaks in the music, suggest that here is something more than mere imitation of the nuances of another's performance. And Romy's tendency on occasion to push expressivity beyond that of her coperformers also hints at a genuinely advanced level of musicality. In terms of musical empathy, it appears that Romy has the capacity and the desire to share a common musical narrative with another person: as a listener, understanding her or his metaphorical emotional-cognitive journey in sound; as a player, knowing how (and wanting) to convey her own interpretations to those around; and as a co-performer, engaging discerningly in empathic creativity. Since Romy is capable of improvising coherently and expressively with musicians with whom she has not worked before, she evidently has musical empathy beyond a few known individuals: she possesses what may be termed 'cultural empathy' in the domain of music (a term coined in the context of multicultural counselling by Ridley and Lingle in 1996). 

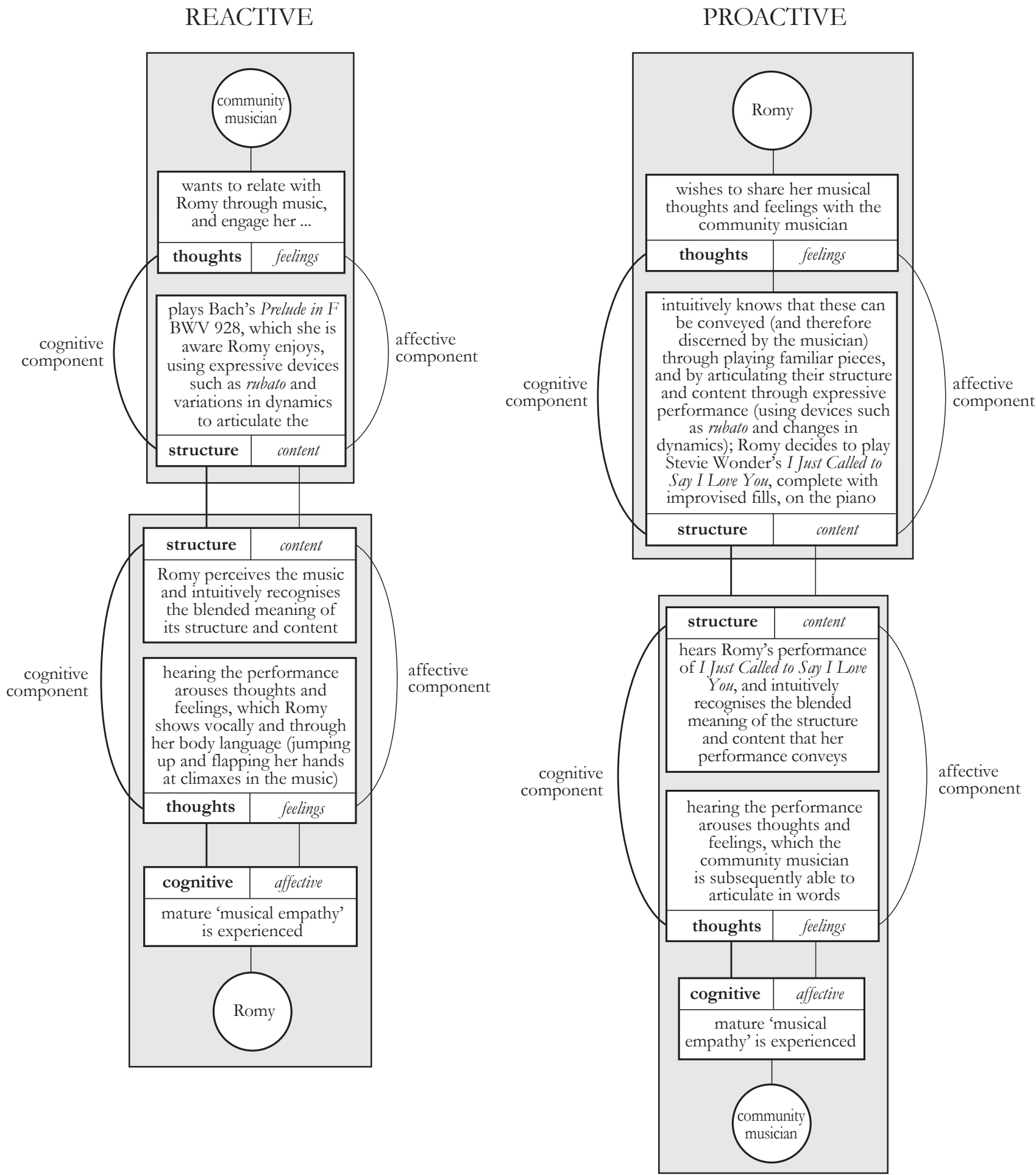

Figure 22 Romy shows mature reactive and proactive musical empathy (Level 6) 


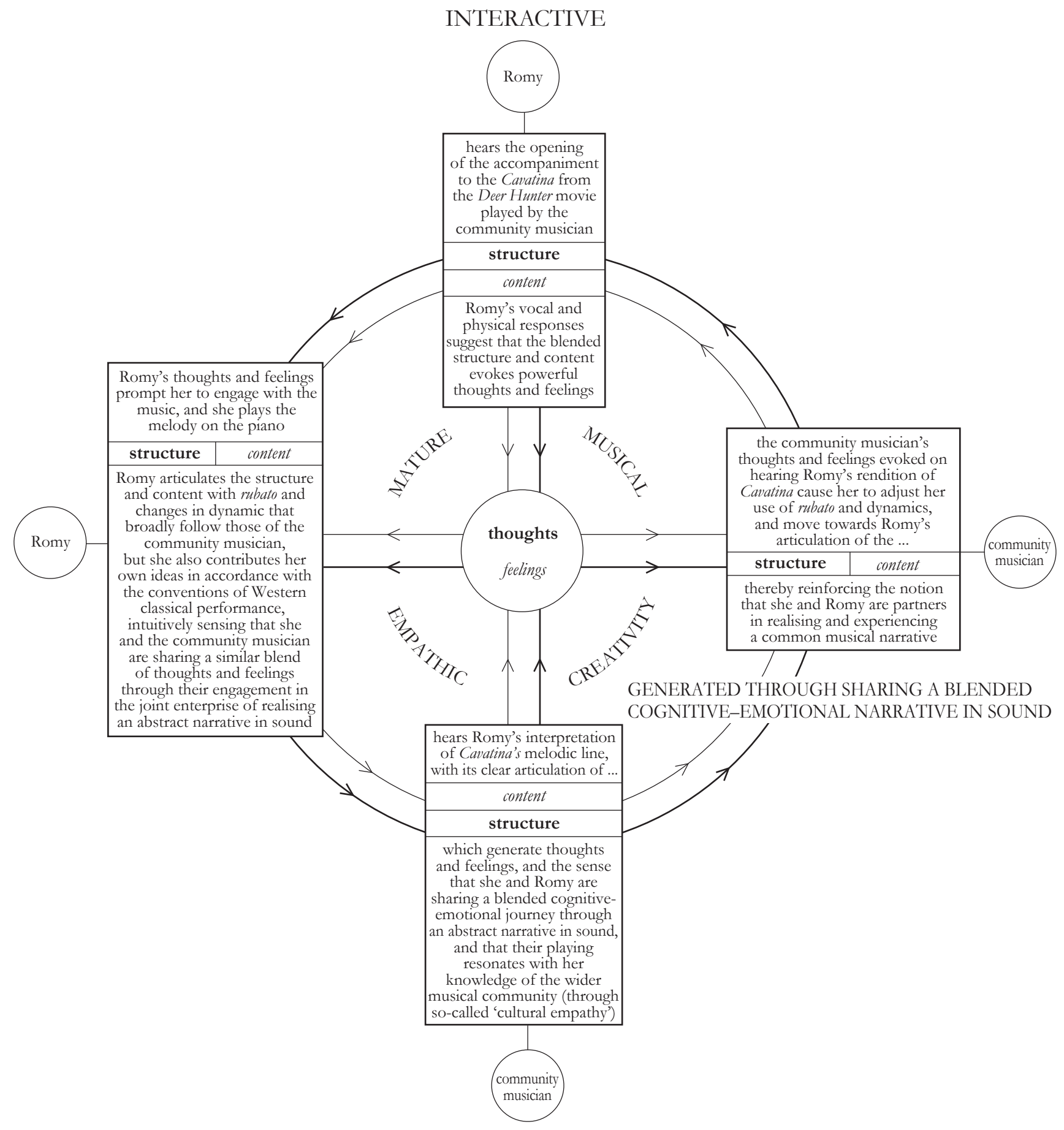

Figure 23 Romy and a community musician share a mature empathic creativity (Level 6).

\section{Discussion}

What do these six scenarios and the analyses tell us?

1. Musical empatby appears to develop as musicality evolves.

The scenarios suggest that there is a correlation between people's developing ability to process, understand and make music and their capacity for behaving empathetically in musical terms. Is 
this a necessary connection, though? The vignettes and corresponding analyses pertain to young people who are consciously not 'neurotypical', since, as we noted above, it is believed that those on the autism spectrum or who have learning difficulties (or both) may, by their very atypicality (including spiky developmental profiles in which the growth of 'everyday' empathy is often inhibited), offer insights that may be obscured in those with a more even spread of intellectual and personality traits. However, the notion of musicality is blind to cerebral 'otherness' (or, indeed, disability): irrespective of individuals' general levels of mental functioning, for them to engage with music is, by definition, for them to engage with the products of other minds. That is to say, one cannot understand music without understanding (albeit intuitively) how other minds work - that is, without musical empathy - whether that manifests itself through joining in with a regular beat (Sounds of Intent, Level 3), chanting on the football terraces (Level 4), singing along with a favourite track on the car radio (Level 5), or anticipating (and relishing) the expressive shifts in tempo of a performance of Elgar's cello concerto (Level 6). What the scenarios suggest is that as musical understanding becomes more advanced, so, necessarily, does musical empathy. Moreover, it is worth noting that it is not so much musical content that changes between levels but structure, which in empathetic terms implies that it is not so much feelings that are likely to evolve as thoughts.

It is of interest to observe that, just as musical engagement moves in broad terms from connection with significant others at Levels 3 and 4, to interaction with increasingly wide groups of peers and fellow music-makers at Levels 4 and 5, and in due course to participation in music-cultural activity at Levels 5 and 6, so musical empathy follows a similar path: from sharing musical thoughts and feelings with other individuals (what may be termed 'interpersonal' musical empathy) to more diverse and less familiar sets of people ('group' musical empathy) and eventually to those within wider society, who may even be strangers ('cultural' musical empathy). The similarity of this conceptualisation with Bronfenbrenner's ecological systems theory (originally set out in 1979) seems inescapable - see Figure 24. 


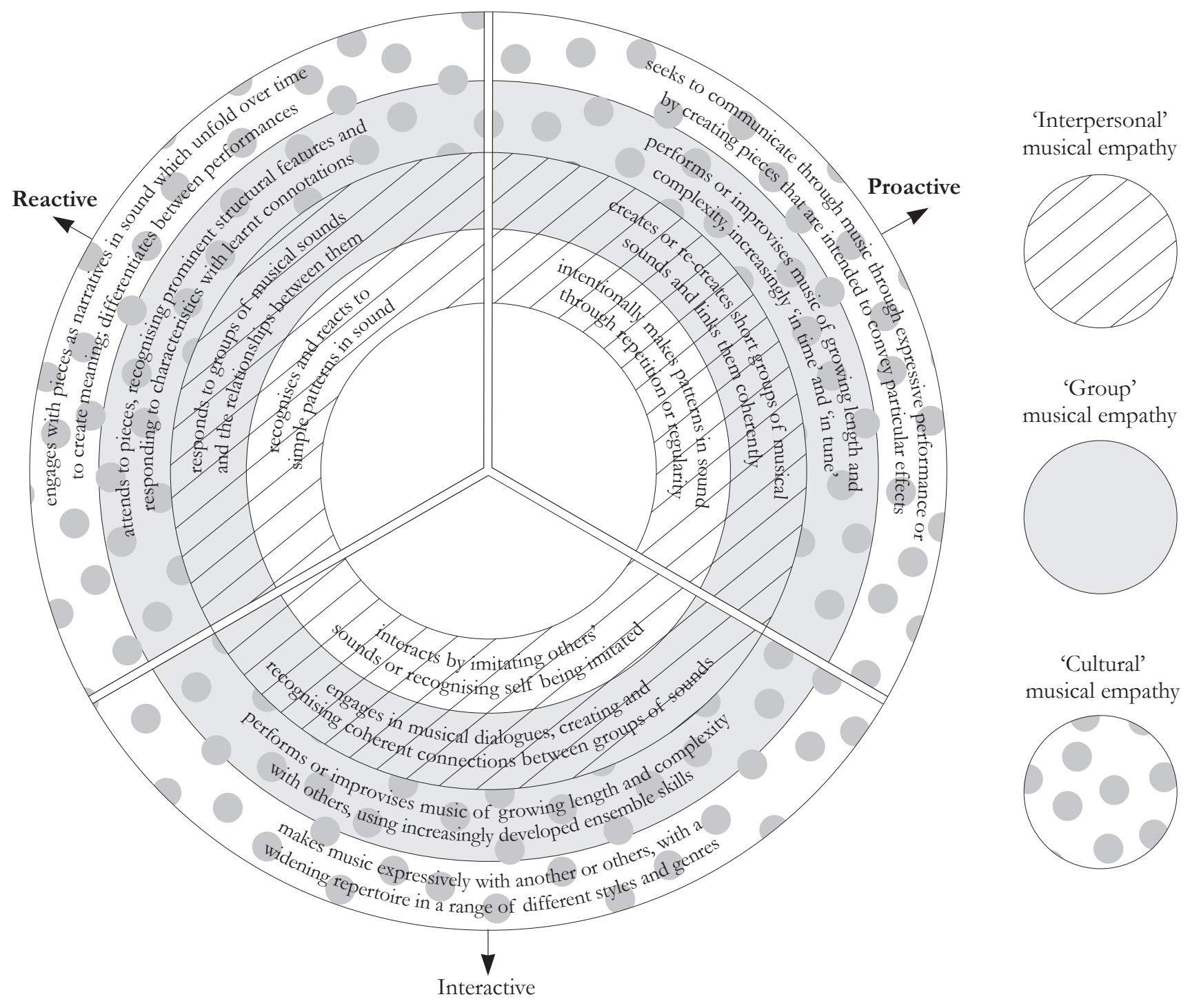

Figure 24 Musical empathy extending further into communities of others with maturation.

2. Musical empathy has two strands: 'affective' and 'cognitive'.

It appears that musical empathy, like 'everyday' empathy, has two distinct strands: cognitive and affective, pertaining to thinking and feeling. It is asserted that these in turn relate to the structure and content of music, as defined in zygonic theory. Both are required in order to create a coherent musical message, through which, metaphorically speaking, empathy can flow. 'Content' - the sheer qualities of sounds - can exist without structure, but such irregular features of the auditory landscape do not comprise music, as we saw in the example of Ethan, functioning at Level 2 of the Sounds of Intent framework of musical development, and experiencing 'proto-musical empathy'. By the same token, musical structure - the sense of imitation through repetition - requires content in order to be reified. Structure can, however, exist in isolation as an abstract concept (as in the notion of 'sonata form', for example), and, in 
terms of styles of listening and performance, as we saw in the case of Freddie (who functions at Sounds of Intent Level 5), attention can largely be devoted to structure at the expense of content: in simple terms, Freddie appears to have a love of repetition for its own sake.

But for most listeners, musical 'thoughts' (as opposed to feelings) apparently exist most if not all of the time beneath the surface of awareness: people can unthinkingly enjoy the emotional narrative of a piece as it flows by in their stream of consciousness without being sensible of its structure. Hence a conceptually naïve though perceptually experienced listener of a Mozart's Jupiter symphony may intuitively delight in the sense of return that the recapitulation brings in the fourth movement, and feel an empathy for the way that, for example, the Chamber Orchestra of Europe under Nikolaus Harnoncourt ushers it in with the subtlest use of rubato in the preceding bar, without consciously being aware that this constitutes a restatement of the opening material. In reality, of course, the feeling of 'coming home' after the peregrinations of the development section is due to the fusion of structure and content generating a blend of thoughts and feelings, and evoking a response that evolves as a combination of affect and cognition; it is just that, in the case of the wholly intuitive listener, the former is foregrounded in consciousness while the latter is less salient. Yet it is safe to assume that Harnoncourt and the musicians of the orchestra, with their advanced musical training, would have recognised the recapitulation on an intellectual level (as well as 'feeling' it). Hence there seems to be an asymmetry in the way that the musicians and many audience members may be perceiving the music. But surely such a mismatch creates difficulties for the notion of musical empathy as defined here? This is the issue to which we next turn our attention.

3. Since those engaging in a common musical activity may do so in different ways and at different levels, so the nature of the musical empathy they experience may differ too.

In the scenarios presented above, those engaging with the children tended to use material that were intended to match their levels of musical development. For example, Chloe's class teacher tapped a regular beat for her to hear and imitate; Drew's music teacher enticed him to participate in musical activity with hooks from his favourite pop songs; and Freddie's piano teacher played him pieces, such as Eye Level, that were saturated with repetition. However, there were also occasions when the adults concerned sensed that their own perception of the music may have differed from that of the children's: Freddie's teacher suspected that he himself paid more attention to the content of the music than did his pupil, for example (for whom, as we have seen, structure appeared to be all important). In fact, it seems almost certain that most of the many thousands of hours of music that the children described in the scenarios are likely to 
have encountered incidentally in everyday life comprised pieces that were not designed with their music-developmental levels in mind, since they are likely largely to have been created and performed by professional musicians functioning at Sounds of Intent Level 6. And of the six children mentioned, only Romy has the capacity to appreciate fully the musical messages that are being conveyed and to experience a mature empathetic response. But what of Amelia, Ethan, Chloe, Drew and Freddie? What reasonable assumptions can we make about their understanding of and reactions to the music they hear, and what musical empathy are they likely to feel?

As we saw in relation to the zygonic analysis of the first movement of Beethoven's $5^{\text {th }}$ Symphony shown in Figure 8, an important feature of the way music works is that structure typically functions on several different levels at once. For instance, we observed that a prerequisite of the cognition of groups of notes (Level 4) is to hear patterning at Level 3 (imitative relationships between individual events), and an awareness of organisation at Level 5 (frameworks) is predicated on the experience of previously having processed the interconnections in the domains of pitch and perceived time between numerous groups (Level 4). Investigation of the ways in which young children engage with music (Voyajolu and Ockelford, n.d.; Ockelford and Voyajolu, n.d.) suggests that the developing brain is capable of extracting simpler musical information from the more complex. For example, a two-and-a-halfyear-old may dance in time to the beat of a song without grasping its overall structure, while a three-year-old may sing along with a repeated motif without being able to reproduce the whole melody of which it forms a part. It seems that, in developmental terms, the brain first searches for simple patterns of repetition and regularity that may exist on a moment-to-moment basis in the music, before seeking out groups, which require a process of eduction somewhat removed from the perceptual surface, and make greater demands on attention and memory. Frameworks require the most mental activity of all, with the abstraction of wholly abstract, probabilistic patterns of intervals that we can assume reside deep in long-term memory. Hence, it seems reasonable to assume that, reactively, in relation to a given performance of a particular piece, children will feel musical empathy in a form that accords with their capacity to process the music rather than necessarily being at the level of those who composed and performed it. And similarly, as youngsters proactively produce music themselves, or interactively make a contribution to a joint musical enterprise, any empathy they experience will be limited by their music-developmental level rather than by what the musical materials potentially have to offer.

For example, let us imagine that Amelia, Ethan, Chloe, Drew, Freddie and Romy are all played a recording of 'When I am laid in earth' from Purcell's Dido and Aeneas, sung by Emma Kirkby. 
What musical empathy is each of them likely to feel? Given that none of them has fully functioning expressive language, the strongest source of evidence is likely to be found in the musical responses that they may make. In Amelia's case, her lack of any reaction to the lament (as to all other sound and music) suggests that she derives nothing from the musical exposure nor, therefore, experiences any empathy. Through emotional contagion, Ethan may feel sadness at points in the melody such as those at which Dido sings 'ah!' in a kind of musical wail and respond with his own cries (see Figure 25). Chloe may show her empathy for Kirkby's performance (at the level of 'here is someone like me') through short busts of entrained moving or tapping to the underlying pulse, particularly when the beat is set out clearly in the vocal line (as in the opening two bars, for example). Drew may pick up on the repeated iambic pairs of descending semitones in the bass and subsequently use these as a resource for improvising, implying a realisation, at some level, that 'here is someone like me who is nonetheless distinct'. Freddie may well recognise the minor mode, though he is not likely to engage with it on an emotional level. However, he may observe that the bass line is repeated throughout, and later enjoy playing this over and over again while he listens to the recording. Freddie's contribution is likely to be loud and boisterous, apparently trying to push the tempo forward in an effort to get to the next iteration as soon as possible! In empathetic terms, we can assume that he has an intuitive sense that Kirkby and her fellow performers are 'like him but different' and able to share a common musical purpose over time. Similarly, after several hearings of the recording, Romy may wish to perform the melody herself on the piano. She is likely to have developed an implicit understanding of the metaphorical narrative of the piece, leading her, like Kirkby, to linger on the climactic top $G$ for expressive effect, as well as emphasising it through a louder dynamic, and reducing the tempo at the end of the (originally instrumental) coda. Hence she will empathise with the performance in a musically mature way. 


\section{Musical empathy}

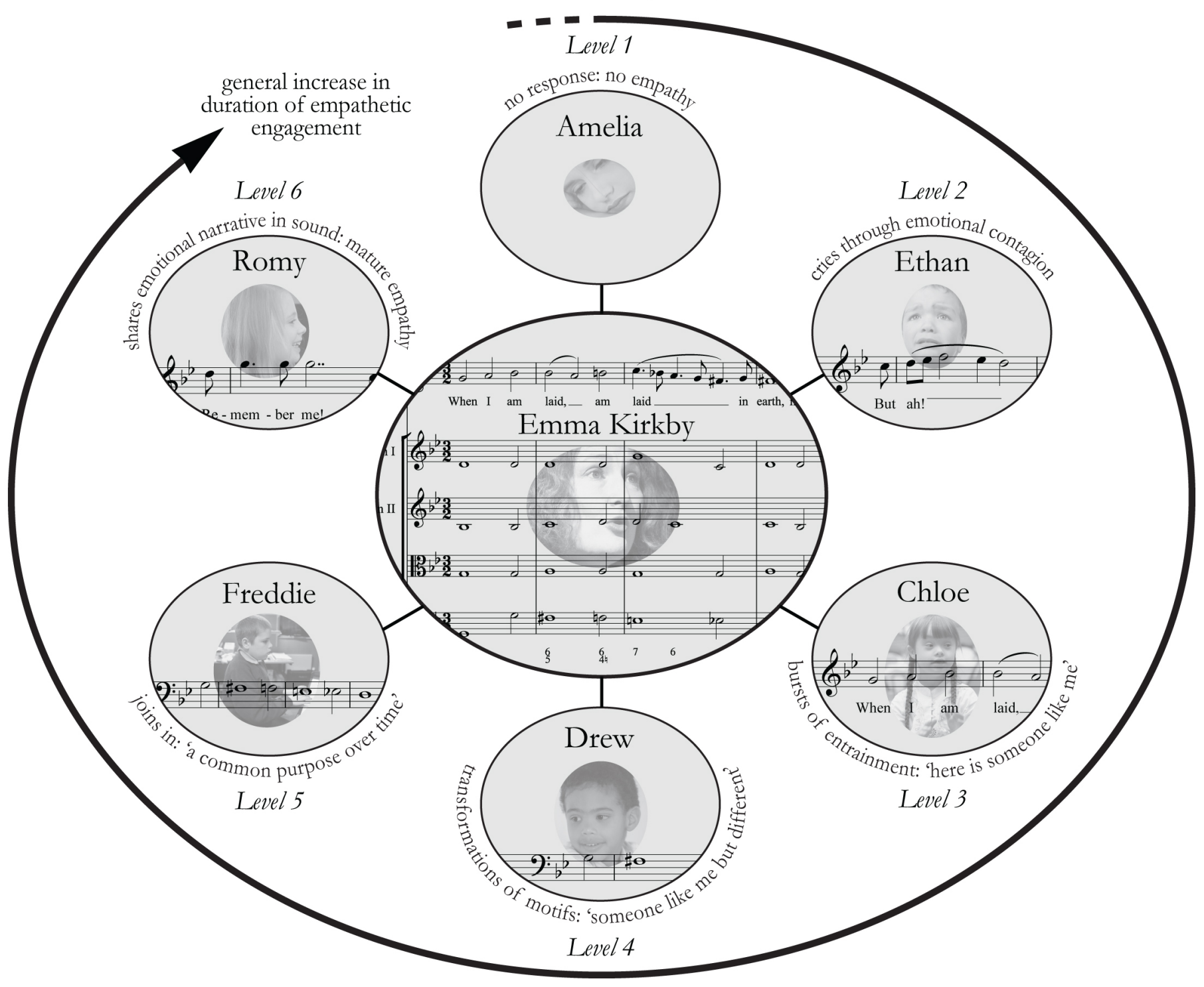

Figure 25 Six levels of musical empathy.

In summary, then, it appears that there are six distinguishable stages of musical empathy, which are inherent in developing musicality, and that the Sounds of Intent levels can potentially function as proxy music-empathetic measures - offering a 'music-empathetic quotient', along the lines of the so-called 'EQ' developed by Baron-Cohen and Wheelwright (2004) and Wakabayashi et al. (2006). It is also worth noting that, generally speaking, there is an increase in the duration of empathetic engagement as musicality matures.

\section{Musical empathy is distinct from and can exist in isolation from 'everyday' empathy}

The examples of children and young people on the autism spectrum and with learning difficulties indicate that empathy that arises from music's structure and content (through 'intra- 
musical' factors) is distinct from everyday empathy, and can exist in isolation from it (see Figure 26). That is not to say, of course, that such a disconnect is the norm: experience suggests that most people, insofar as they can appreciate music, have musical empathy in addition to the general kind. Whether, and if so how, these two mental phenomena interact should be the subject of future research, which could be of particular value for those working with children on the autism spectrum, since it may facilitate the development of pedagogical strategies through which musical empathy could be used to promote empathy in other-than-musical contexts. Conversely, it may also be the case, to the extent that there are some people who do not appear to like music or wish to engage with it at all, for musical empathy to be limited or even absent. Again, this is an area requiring further research.

Finally, to the extent that musical meaning can be generated through the association of particular pieces or excerpts with events, places or people ('extra-musical' factors), it is possible for everyday empathy to be elicited through music on account of an extra-musical symbolic connection (rather in the way that verbal narratives can evoke empathy through the meaning of the words rather than their sounds, although onomatopoeia may play a subsidiary role). This was the case with Drew's music teacher (see Figure 18) who played him the hook of a pop song since he was aware that this had pleasant associations for Drew on account of his father's band playing it. One could imagine other cases in which one was cognisant of people's likely reactions to pieces that had been played at a happy occasion (their wedding, for example), or a sad one, such as a close friend's funeral. 


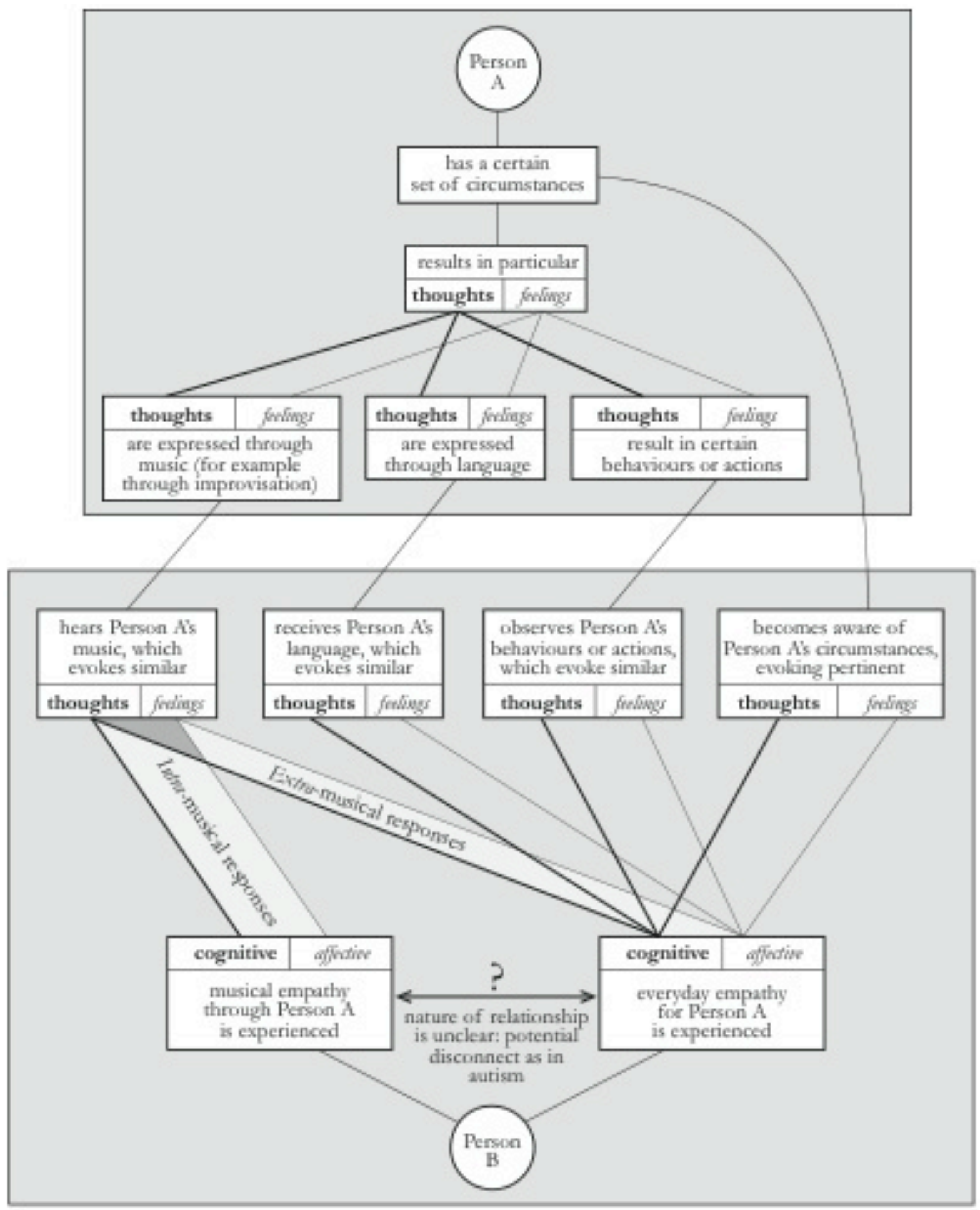

Figure 26 Modelling the relationship between everyday empathy and musical empathy.

Conclusion

The foregoing case studies and discussion enable us construct a general model of musical empathy, by detailing the nature of the relationship between composer and performer (or improviser) and listener. This is shown in Figure 27, where the following sequence of events is illustrated. First, a composer creates music, by producing particular structure and content in the 
domain of sound, which he or she will be aware can convey certain thoughts and feelings. Sometimes, the desire to express (and communicate) particular musical thoughts and feelings may dictate the choice of structure and content (in the case of composers of film music, for example). Performers take the information about the new music provided by the composer (either indirectly through notation or directly through hearing it played or sung) and add their own layer of interpretation through expressive devices such as rubato, vibrato and variations in timbre and dynamics. The result is a fusion of structure and content, which elicits a blend of thoughts and feelings that makes up an 'aesthetic response'. In the case of improvisation, this synthesis (and the creation of an aesthetic response) occurs in the moment.

Listeners perceive the integrated flow of musical structure and content over time, which in turn evokes a combination of thoughts and feelings that constitutes their own aesthetic response. To the extent that this is similar to that which the composer and performer (or improviser) intended to be conveyed, so the listener can be said to have 'musical empathy' with the creator and re-creator of the music. 


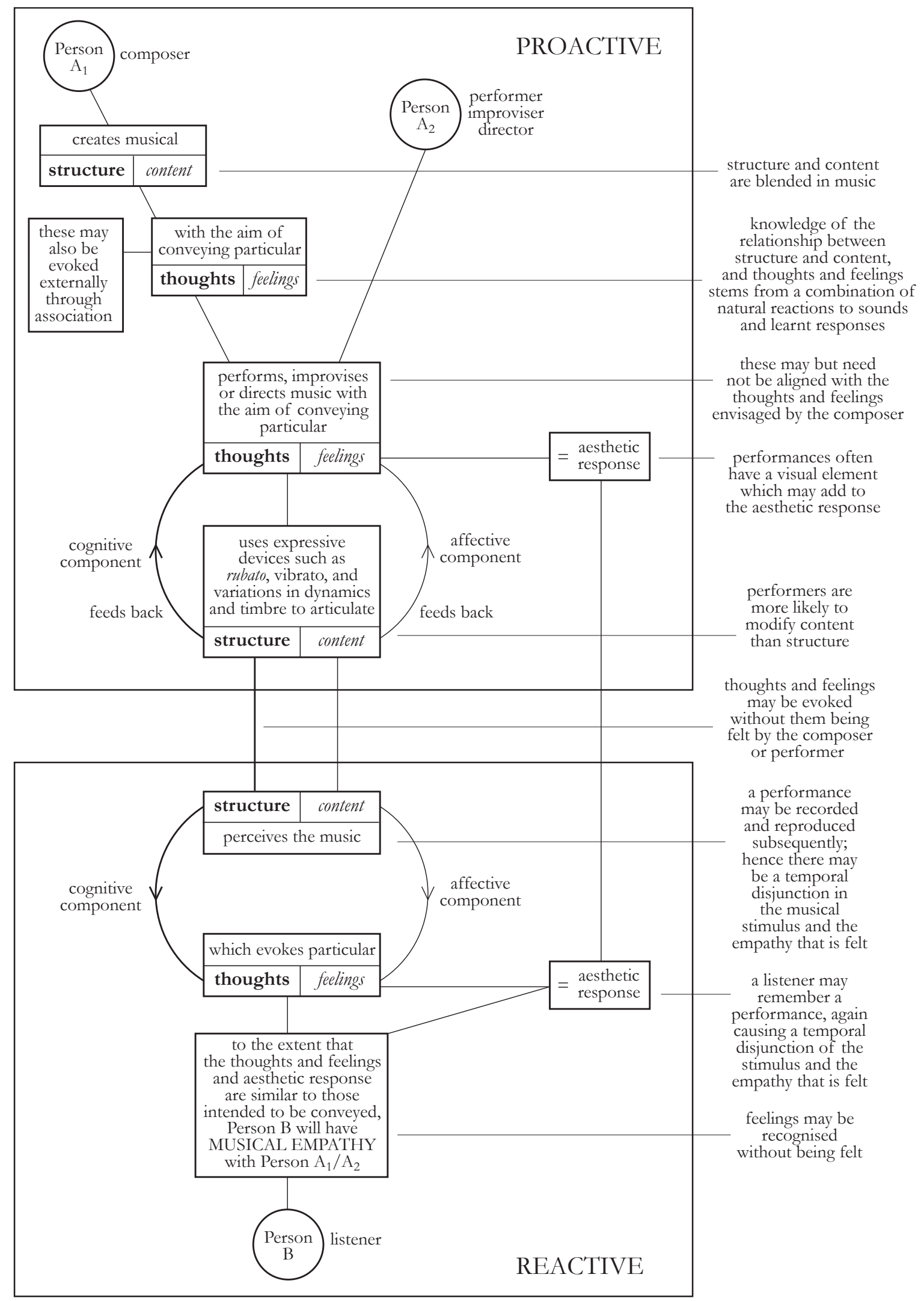

Figure 27 A model of mature musical empathy (proactive and reactive).

In the case of two people (or more) improvising together, the model may be modified as shown in Figure 28. As we noted above, the result is 'empathic creativity' (Cross, Laurence and

Rabinowitch, 2012). 
INTERACTIVE

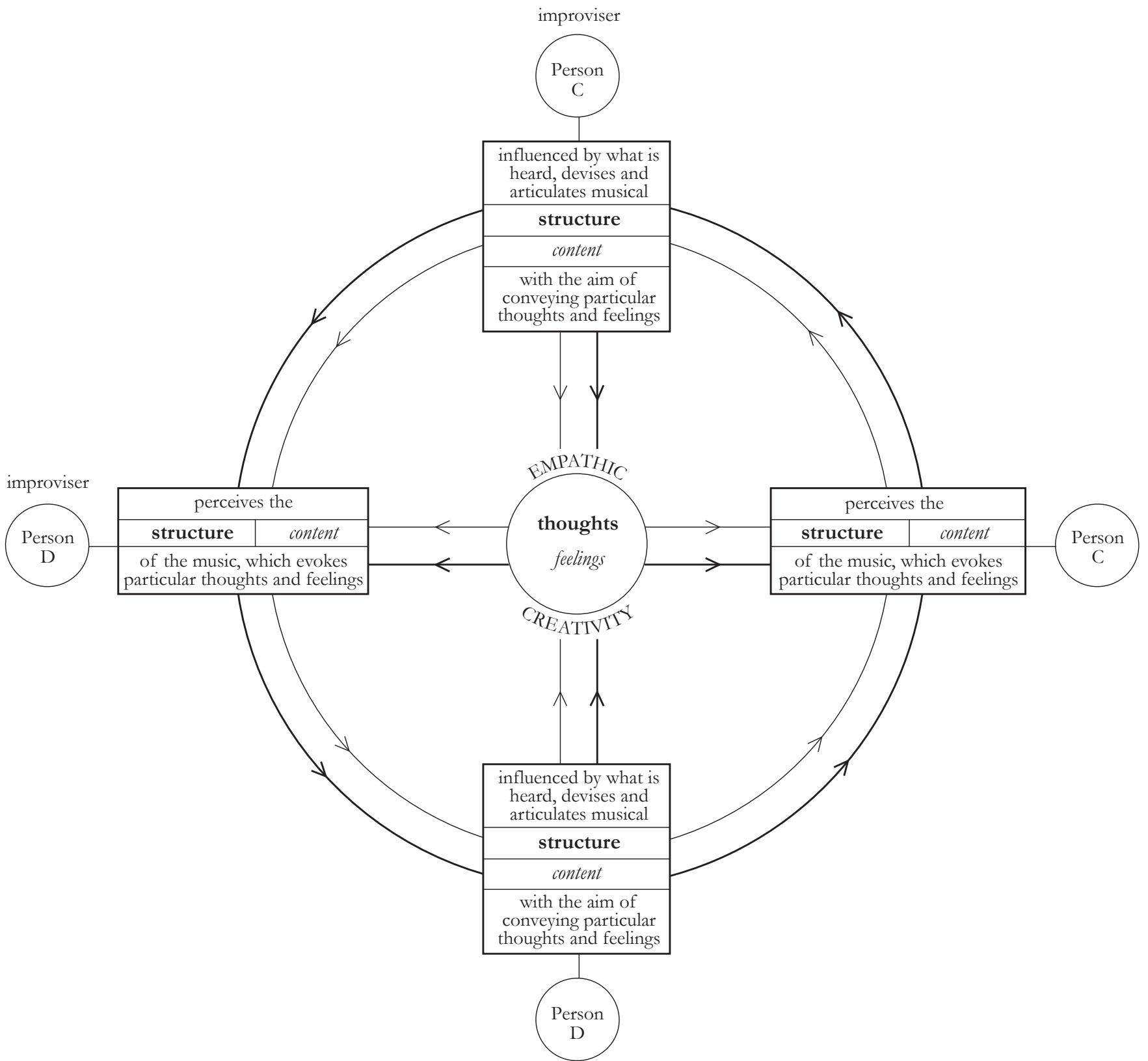

Figure 28 A model of mature musical empathy (interactive). 


\section{Bibliography}

Balkwill, L. and Thompson, W. (1999). A Cross-Cultural Investigation of the Perception of Emotion in Music: Psychophysical and Cultural Cues. Music Perception: An Interdisciplinary Journal, 17(1), pp.43-64.

Baron-Cohen, S. (1997). Mindblindness. Cambridge, Mass.: MIT Press.

Baron-Cohen, S. and Wheelwright, S. (2004). The Empathy Quotient: An Investigation of Adults with Asperger Syndrome or High Functioning Autism, and Normal Sex Differences. J Autism Dev Disord, 34(2), pp.163-175.

Bharucha, J. (1987). Music Cognition and Perceptual Facilitation: A Connectionist Framework. Music Perception: An Interdisciplinary Journal, 5(1), pp.1-30.

Boucher, J. (2008). Characteristics, Causes and Practical Issues. London: Sage Publications Ltd. Bronfenbrenner, U. (1979). The Ecology of Human Development. Cambridge, Mass.: Harvard University Press.

Carr, L., Iacoboni, M., Dubeau, M., Mazziotta, J. and Lenzi, G. (2003). Neural mechanisms of empathy in humans: A relay from neural systems for imitation to limbic areas. Proceedings of the National Academy of Sciences, 100(9), pp.5497-5502.

Cattaneo, L. and Rizzolatti, G. (2009). The Mirror Neuron System. Archives of Neurology, 66(5).

Cheng, E., Ockelford, A. and Welch, G. (2009). Researching and developing music provision in special schools in England for children and young people with complex needs. Australian Journal of Music Education, 2009(2), pp.27-48.

Coplan, A. (2011). Understanding empathy: its features and effects. In: A. Coplan and P. Goldie, ed., Empathy: Philosophical and Psychological Perspectives, 1st ed. Oxford: Oxford University Press, pp.3-18.

Cross, I., Laurence, F. and Rabinowitch, T. (2011). Empathic creativity in musical group practices. In: G. McPherson and G. Welch, ed., The Oxford Handbook of Music Education, 1st ed. New York: Oxford University Press, pp.337-353.

Crowder, R. (1985). Perception of the major/minor distinction: III. Hedonic, musical, and affective discriminations. Bull. Psychon. Soc., 23(4), pp.314-316.

Davis, M. (1996). Empathy. Boulder (Colo.): Westview Press.

de Selincourt, B. (1920). Music and duration. Music and Letters, 1(4).

de Waal, F. (2008). Putting the altruism back into altruism: The evolution of empathy. Annu. Rev. Psychol., 59(1), pp.279-300.

Decety, J. (2004). The functional architecture of human empathy. Behavioral and Cognitive Neuroscience Reviews, 3(2), pp.71-100. 
di Pellegrino, G., Fadiga, L., Fogassi, L., Gallese, V. and Rizzolatti, G. (1992). Understanding motor events: A neurophysiological study. Exp Brain Res, 91(1), pp.176-180.

Eliot, T. (1933). The Use of Poetry and the Use of Criticism. Cambridge, Mass.: Harvard University Press.

Eliot, T. (1960). The Sacred Wood. London: Methuen.

Fan, Y., Decety, J., Yang, C., Liu, J. and Cheng, Y. (2010). Unbroken mirror neurons in autism spectrum disorders. Journal of Child Psychology and Psychiatry, 51(9), pp.981-988.

Frith, U. (2003). Explaining the Enigma. Oxford: Blackwell.

Gabrielsson, A. and Lindström, S. (2000). The influence of musical structure on emotional expression. In: P. Juslin and J. Sloboda, ed., Music and Emotion: Theory and Research, 1 st ed. New York: Oxford University Press, pp.223-248.

Gallagher, S. (2000). Philosophical conceptions of the self: implications for cognitive science. Trends in Cognitive Sciences, 4(1), pp.14-21.

Gallese, V. (2003). The roots of empathy: The shared manifold hypothesis and the neural basis of intersubjectivity. Psychopathology, 36(4), pp.171-180.

Gallese, V., Fadiga, L., Fogassi, L. and Rizzolatti, G. (1996). Action recognition in the premotor cortex. Brain, 119(2), pp.593-609.

Gazzola, V., Aziz-Zadeh, L. and Keysers, C. (2006). Empathy and the somatotopic auditory mirror system in humans. Current Biology, 16(18), pp.1824-1829.

Goldman, A. (2011). Two routes to empathy: insights from cognitive neuroscience. In: A. Coplan and P. Goldie, ed., Empathy: Philosophical and Psychological Perspectives, 1 st ed. Oxford: Oxford University Press, pp.31-44.

Greenberg, D., Renfrew, P. and Baron-Cohen, S. (2015). Can music increase empathy? Interpreting musical experience through the empathizing-systematizing (E-S) theory. Empirical Musicology Review, 10(1), pp.79-94.

Gundlach, R. (1935). Factors Determining the Characterization of Musical Phrases. The American Journal of Psychology, 47(4), p.624.

Hadjikhani, N. (2005). Anatomical differences in the mirror neuron system and social cognition network in autism. Cerebral Cortex, 16(9), pp.1276-1282.

Håkansson, J. (2003). Exploring the phenomenon of empathy. Stockholm: Dept. of Psychology [Psykologiska institutionen], Univ.

Happé, F. (1998). Autism: An Introduction to Psychological Theory. Cambridge, Mass.: Harvard University Press.

Heaton, P., Hermelin, B. and Pring, L. (1999). Can children with autistic spectrum disorders perceive affect in music? An experimental investigation. Psychological Medicine, 29(6), pp.1405-1410. 
Hevner, K. (1936). Experimental studies of the elements of expression in music. The American Journal of Psychology, 48(2), p.246.

Iacoboni, M. (2009). Imitation, empathy, and mirror neurons. Annu. Rev. Psychol., 60(1), pp.653670.

Jairazbhoy, N. and Khan, V. (1971). The Rāgs of North Indian music. Middletown, Conn.: Wesleyan University Press.

Johnson-Laird, P. and Oatley, K. (1992). Basic emotions, rationality, and folk theory. Cognition \& Emotion, 6(3), pp.201-223.

Juslin, P. (1997). Perceived emotional expression in synthesized performances of a short melody: capturing the listener's judgement policy. Musicae Scientiae, 1(1), pp.225-256.

Juslin, P. (2001). Communicating emotion in music performance: a review and a theoretical framework. In: P. Juslin and J. Sloboda, ed., Music and Emotion: Theory and Research, 1st ed. New York: Oxford University Press, pp.309-337.

Juslin, P. and Västfjäll, D. (2008). Emotional responses to music: The need to consider underlying mechanisms. Behavioral and Brain Sciences, 31(06), p.751.

Juslin, P., Friberg, A. and Bresin, R. (2001). Toward a computational model of expression in music performance: The GERM model. Musicae Scientiae, 5(1 suppl), pp.63-122.

Keysers, C. (2011). The Empathic Brain. Lexington, Ky.: Social Brain Press.

Kohler, E. (2002). Hearing sounds, understanding actions: Action representation in mirror neurons. Science, 297(5582), pp.846-848.

Krumhansl, C. (1997). An exploratory study of musical emotions and psychophysiology. Canadian Journal of Experimental Psychology/Revue canadienne de psychologie expérimentale, 51(4), pp.336-353.

Livingstone, R. and Thompson, W. (2009). The emergence of music from the theory of mind. Musicae Scientiae, 13 (2 Suppl), pp.83-115.

Malloch, S. (1999). Mothers and infants and communicative musicality. Musicae Scientiae, 3(1 suppl), pp.29-57.

Martin, G. and Clark, R. (1982). Distress crying in neonates: Species and peer specificity. Developmental Psychology, 18(1), pp.3-9.

McDonald, N. and Messinger, D. (2011). The development of empathy: how, when, and why. In: J. Sanguineti, A. Acerbi and J. Lombo, ed., 1st ed. Rome: IF Press, pp.333-361.

Meltzoff, A. (1990). Foundations for developing a concept of self: the role of imitation in relating self to other and the value of social mirroring, social modeling, and self practice in infancy. In: D. Cicchetti and M. Beeghly, ed., The Self in Transition: Infancy to Childhood, 1st ed. Chicago: University of Chicago Press, pp.139-164. 
Meltzoff, A. (1995). Understanding the intentions of others: Re-enactment of intended acts by 18-month-old children. Developmental Psychology, 31(5), pp.838-850.

Meltzoff, A. (2002). Elements of a developmental theory of imitation. In: A. Meltzoff and W. Prinz, ed., The Imitative Mind: Development, Evolution, and Brain Bases, 1st ed. Cambridge: Cambridge University Press, pp.19-41.

Meltzoff, A. (2007). The 'like me' framework for recognizing and becoming an intentional agent. Acta Psychologica, 124(1), pp.26-43.

Meltzoff, A. and Moore, M. (1983). Newborn infants imitate adult facial gestures. Child Development, 54(3), p.702.

Meltzoff, A. and Moore, M. (1989). Imitation in newborn infants: Exploring the range of gestures imitated and the underlying mechanisms. Developmental Psychology, 25(6), pp.954962.

Meyer, L. (1989). Style and Music. Philadelphia: University of Pennsylvania Press.

Meyer, L. (2001). Music and emotion: Distinctions and uncertainties. In: P. Juslin and J. Sloboda, ed., Music and Emotion: Theory and Research, 1st ed. New York: Oxford University Press, pp.341-360.

Miall, R. (2003). Connecting mirror neurons and forward models. NeuroReport, 14(17), pp.21352137.

Nemoto, I., Fujimaki, T. and Wang, L. (2010). fMRI measurement of brain activities to major and minor chords and cadence sequences. 2010 Annual International Conference of the IEEE Engineering in Medicine and Biology, 2010, pp.5640-5643.

Nielzen, S. and Cesarec, Z. (1982). Emotional experience of music as a function of musical structure. Psychology of Music, 10(2), pp.7-17.

Oberman, L., Hubbard, E., McCleery, J., Altschuler, E., Ramachandran, V. and Pineda, J. (2005). EEG evidence for mirror neuron dysfunction in autism spectrum disorders. Cognitive Brain Research, 24(2), pp.190-198.

Ockelford, A. (1991). The role of repetition in perceived musical structures. In: P. Howell, R. West and I. Cross, ed., Representing Musical Structure, 1st ed. London: Academic Press, pp.129-160.

Ockelford, A. (2002). Objects of Reference. 3rd ed. London: Royal National Institute for the Blind.

Ockelford, A. (2005). Relating musical structure and content to aesthetic response: A model and analysis of Beethoven's Piano Sonata Op. 110. Journal of the Royal Musical Association, 130(1), pp.74-118.

Ockelford, A. (2006). Implication and expectation in music: a zygonic model. Psychology of Music, 34(1), pp.81-142. 
Ockelford, A. (2008). Music for Children and Young People with Complex Needs. Oxford, England: Oxford University Press.

Ockelford, A. (2011). Another exceptional musical memory: Evidence from a savant of how atonal music is processed in cognition. In: I. Deliège, ed., Music and the Mind: A Book to Honour the Achievements of John Sloboda, 1st ed. Oxford: Oxford University Press, pp.237288.

Ockelford, A. (2012). Applied Musicology. Oxford: Oxford University Press.

Ockelford, A. (2013). Music, Language and Autism. London: Jessica Kingsley Publishers.

Ockelford, A. and Matawa, C. (2009). Focus on Music 2. London: Institute of Education, University of London.

Ockelford, A. and Vorhaus, J. (2015). Identity and musical development in people with severe or profound and multiple learning difficulties. In: R. MacDonald, D. Hargreaves and D. Miell, ed., The Oxford Handbook of Musical Identities, 1st ed. New York: Oxford University Press.

Ockelford, A. and Voyajolu, A. (n.d.). The emergence of musical abilities in the early years: A perspective using the Sounds of Intent model. In: A. Ockelford and G. Welch, ed., New Approaches to Analysis in Music Psychology and Education Research Using Zygonic Theory, 1st ed. Farnham: Ashgate.

Ockelford, A. and Welch, G. (2012). What can musical engagement in children with cognitive impairment tell us about their sense of self?. In: S. O'Neill, ed., Personhood and Music Learning: Connecting Perspectives and Narratives, 1st ed. Waterloo, Ontario: Canadian Music Educators' Association, pp.216-237.

Ockelford, A., Welch, G., Jewell-Gore, L., Cheng, E., Vogiatzoglou, A. and Himonides, E. (2011). Sounds of Intent, phase 2: Gauging the music development of children with complex needs. European Journal of Special Needs Education, 26(2), pp.177-199.

Ockelford, A., Welch, G., Zimmermann, S. and Himonides, E. (2005). 'Sounds of Intent': Mapping, assessing and promoting the musical development of children with profound and multiple learning difficulties. International Congress Series, 1282, pp.898-902.

Peretz, I. (1998). Music and emotion: perceptual determinants, immediacy, and isolation after brain damage. Cognition, 68(2), pp.111-141.

Preston, S. and de Waal, F. (2001). Empathy: Its ultimate and proximate bases. Behavioral and Brain Sciences, 25(1).

Ramachandran, V. and Oberman, L. (2006). Broken Mirrors: A Theory of Autism. Sci Am, 295(5), pp.62-69. 
Ridley, C. and Lingle, D. (1996). Counseling across cultures. In: P. Pedersen, J. Draguns, W. Lonner and J. Trimble, ed., Cultural empathy in multicultural counseling: A multidimensional process model, 4th ed. Thousand Oaks, CA: Sage, pp.21-46.

Rizzolatti, G. and Fabbri-Destro, M. (2009). Mirror neurons: from discovery to autism. Exp Brain Res, 200(3-4), pp.223-237.

Rizzolatti, G., Fadiga, L., Gallese, V. and Fogassi, L. (1996). Premotor cortex and the recognition of motor actions. Cognitive Brain Research, 3(2), pp.131-141.

Sagi, A. and Hoffman, M. (1976). Empathic distress in the newborn. Developmental Psychology, 12(2), pp.175-176.

Scherer, K. (1991). Emotion expression in speech and music. In: J. Sundberg, L. Nord and R. Carlson, ed., Music, Language, Speech and Brain, 1st ed. London: MacMillan, pp.146-156.

Scherer, K. and Oshinsky, J. (1977). Cue utilization in emotion attribution from auditory stimuli. Motivation and Emotion, 1(4), pp.331-346.

Scherer, K., Banse, R. and Wallbott, H. (2001). Emotion inferences from vocal expression correlate across languages and cultures. Journal of Cross-Cultural Psychology, 32(1), pp.76-92.

Seddon, F. (1999). Modes of communication during jazz improvisation. Brit. J. Music. Ed., 22(1), pp.47-61.

Shamay-Tsoory, S., Aharon-Peretz, J. and Perry, D. (2009). Two systems for empathy: A double dissociation between emotional and cognitive empathy in inferior frontal gyrus versus ventromedial prefrontal lesions. Brain, 132(3), pp.617-627.

Simner, M. (1971). Newborn's response to the cry of another infant. Developmental Psychology, 5(1), pp.136-150.

Sparshott, F. (1994). Music and feeling. Journal of Aesthetics and Art Criticism, 52(1), pp.23-35.

Suzuki, M., Okamura, N., Kawachi, Y., Tashiro, M., Arao, H., Hoshishiba, T., Gyoba, J. and Yanai, K. (2008). Discrete cortical regions associated with the musical beauty of major and minor chords. Cognitive, Affective, \& Behavioral Neuroscience, 8(2), pp.126-131.

Thompson, W. and Robitaille, B. (1992). Can composers express emotions through music?. Empirical Studies of the Arts, 10(1), pp.79-89.

Trehub, S. and Nakata, T. (2015). Emotion and music in infancy. Musicae Scientiae, 5(1 suppl), pp.37-61.

Vogiatzoglou, A., Ockelford, A., Welch, G. and Himonides, E. (2011). Sounds of Intent: Interactive software to assess the musical development of children and young people with complex needs. Music and Medicine, 3(3), pp.189-195.

Voyajolu, A. and Ockelford, A. (n.d.). Sounds of Intent in the early years: A proposed framework of young children's musical development. Research Studies in Music Education. 
Wakabayashi, A., Baron-Cohen, S., Wheelwright, S., Goldenfeld, N., Delaney, J., Fine, D., Smith, R. and Weil, L. (2006). Development of short forms of the Empathy Quotient (EQ-Short) and the Systemizing Quotient (SQ-Short). Personality and Individual Differences, 41(5), pp.929-940.

Wan, C., Demaine, K., Zipse, L., Norton, A. and Schlaug, G. (2010). From music making to speaking: Engaging the mirror neuron system in autism. Brain Research Bulletin, 82(3-4), pp.161-168.

Watson, K. (1942). The nature and measurement of musical meanings. Psychological Monographs, 54(2), p.i-43.

Welch, G., Ockelford, A., Carter, F., Zimmermann, S. and Himonides, E. (2009). 'Sounds of Intent': mapping musical behaviour and development in children and young people with complex needs. Psychology of Music, 37(3), pp.348-370.

Williams, J., Waiter, G., Gilchrist, A., Perrett, D., Murray, A. and Whiten, A. (2006). Neural mechanisms of imitation and 'mirror neuron' functioning in autistic spectrum disorder. Neuropsychologia, 44(4), pp.610-621.

Winner, E. (1996). Gifted Children. New York: Basic Books.

Zahn-Waxler, C. and Radke-Yarrow, M. (1990). The origins of empathic concern. Motivation and Emotion, 14(2), pp.107-130. 